\title{
Ventilation of the Miocene Arctic Ocean: An idealized model study
}

\author{
Bijoy Thompson, ${ }^{1}$ Johan Nilsson, ${ }^{2}$ Jonas Nycander, ${ }^{2}$ Martin Jakobsson, ${ }^{1}$ \\ and Kristofer Döös ${ }^{2}$ \\ Received 28 October 2009; revised 9 July 2010; accepted 23 July 2010; published 24 November 2010.
}

[1] A model study of an idealized early Miocene Arctic Ocean has been undertaken. The work is motivated by the first drill core retrieved from the Lomonosov Ridge in the central Arctic Ocean, which suggests a transition from anoxic to oxic condition during the early Miocene, a feature presumably related to the opening of the Fram Strait. Here, the ventilation in a semienclosed basin, connected with the ocean through a strait with a sill, is examined using an ocean circulation model that includes a passive age tracer. In particular, we investigate how the ventilation depends on strait geometry, freshwater influx, and surface wind stress. We find that the turnover time, characterizing the bulk ventilation rate, is primarily controlled by the strait width and the wind stress. Generally, the oldest water in the basin is encountered near the sill depth, but wind forcing displaces the oldest water downward. For narrow straits, the turnover time gives an upper bound on the mean age of the basin water. The results have implications when translating local oxygen conditions, recorded in the sediment sequence from the Lomonosov Ridge, to basin-scale circulation patterns. Further, the results indicate that the early Miocene Arctic Ocean became well ventilated when the Fram Strait reached a width of about $100 \mathrm{~km}$.

Citation: Thompson, B., J. Nilsson, J. Nycander, M. Jakobsson, and K. Döös (2010), Ventilation of the Miocene Arctic Ocean: An idealized model study, Paleoceanography, 25, PA4216, doi:10.1029/2009PA001883.

\section{Introduction}

[2] Oceanic gateways are of critical importance for the paleoceanographic development of the world's oceans and seas. For example, when the Mediterranean Sea became isolated from the Atlantic Ocean 5.6 million years ago (Ma) a period of severe evaporation commenced referred to as the Messinian salinity crisis [Hsü et al., 1973; Krijgsman et al., 1999]. The paleoceanographic conditions in the Mediterranean Sea changed again dramatically when tectonic subsidence of the Gibraltar Strait [Govers, 2009] allowed the Atlantic to breach the strait during the Zanclean flood event $5.33 \mathrm{Ma}$ [Garcia-Castellanos et al., 2009]. Another oceanic gateway of paleoceanographic significance is the Fram Strait located between northeast Greenland and Svalbard where it with a present sill depth of $2550 \mathrm{~m}$ [Klenke and Schenke, 2002] forms the only deep water connection between the Arctic and Atlantic Oceans. The tectonic history of the Fram Strait is of equal importance for the paleoceanographic development of the Arctic Ocean as the Gibraltar Strait is for the Mediterranean Sea. Plate tectonic reconstructions suggest that the Arctic Ocean was completely isolated from the world oceans during early Cenozoic [Vogt et al., 1979; Engen et al., 2008]. The establishment of a deep water connection through the Fram Strait occurred first when seafloor spreading connected the Mid-Atlantic Ridge with the Arctic Gakkel

\footnotetext{
${ }^{1}$ Department of Geological Sciences, Stockholm University, Stockholm, Sweden.

${ }^{2}$ Department of Meteorology, Stockholm University, Stockholm, Sweden.

Copyright 2010 by the American Geophysical Union. 0883-8305/10/2009PA001883
}

Ridge. The first well-developed magnetic anomaly that can be distinguished through the Fram Strait is from around Chron 5 times (9.8 Ma; late Miocene) [Engen et al., 2008], although the paleoceanographic influence of the strait opening began already more than 7 million years earlier in the early Miocene [Backman and Moran, 2009; Jakobsson et al., 2007; Kaminski et al., 2009].

[3] Following the land-locked state and before the deep water connection was fully established, the Arctic Ocean must have communicated with the North Atlantic Ocean during a transition period through a narrow and presumably shallow Fram Strait [Engen et al., 2008]. When the strait opened sufficiently, an estuarine circulation could be established where saline waters of oceanic origin presumably filled the deeper part of the basin, while the surface waters remained relatively fresh [Jakobsson et al., 2007]. Strong salinity stratification in combination with restricted exchange with the Atlantic should have resulted in a long turnover time of the water in the deeper parts of the basin, hereby causing euxinic conditions. Thus, the circulation in the land-locked Arctic Ocean during the times when the Fram Strait began to open may broadly have resembled that in the present-day Black Sea, which is characterized by a shallow and narrow strait, strong salinity stratification, and poorly oxygenated subsurface waters [Stanev, 2005]. As the Fram Strait opened up further, the Arctic Ocean presumably maintained a stable salinity stratification, which inhibited ventilation through winter convection. However, due to enhanced import of oxygen-rich water from the Atlantic Ocean through the Fram Strait, the subsurface waters in the Arctic Ocean eventually became oxygenated (Figure 1). It is obvious that the Arctic Ocean Neogene paleoceanography is closely related to tectonic evolution of the North Atlantic. The sill 
a

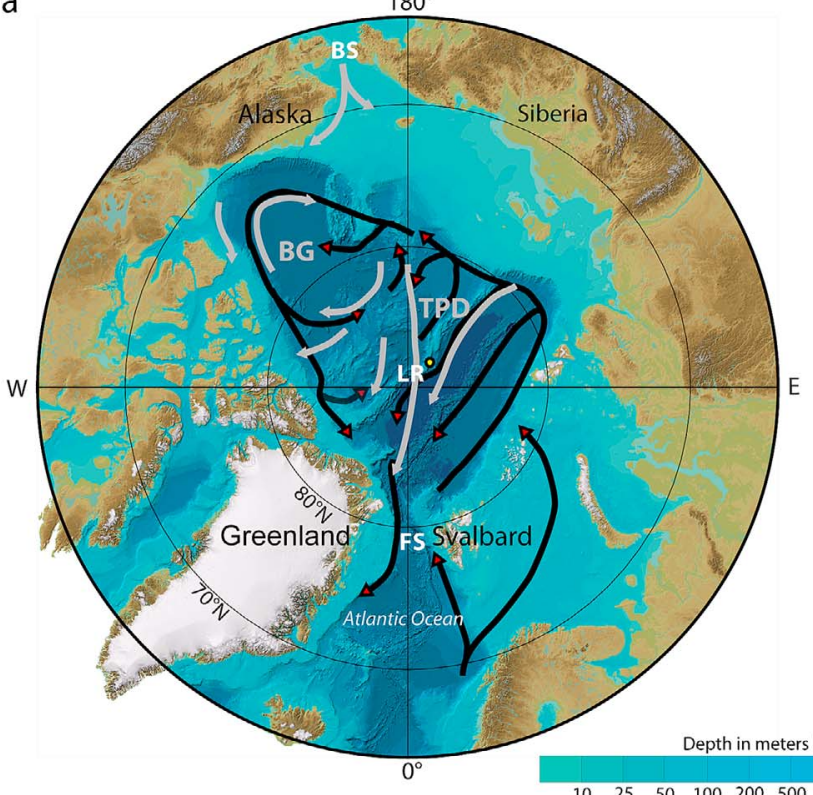

b

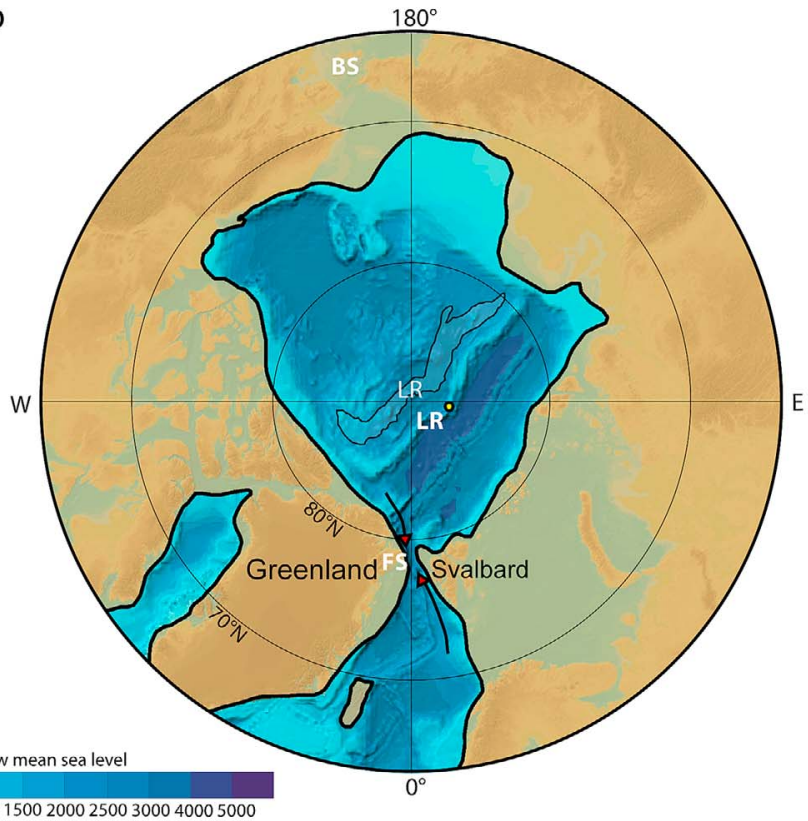

Figure 1. (a) Schematic circulation patterns of Atlantic (black arrows) and surface (gray arrows) waters in the present Arctic Ocean inferred from Rudels et al. [2010]. The location of the ACEX core on the Lomonosov Ridge (LR) is shown with a yellow dot. The bathymetry is from the International Bathymetric Chart of the Arctic Ocean (IBCAO) [Jakobsson et al., 2008]. (b) Paleobathymetric reconstruction of the early Miocene from Jakobsson et al. [2007]. The ACEX coring location estimated for the early Miocene is shown with a yellow dot.

deepening of the Greenland-Iceland-Faroe ridge system occurred in the early Oligocene when the Feni and Southeast Faeroes sediment drifts begun forming suggesting a southward deep-water flow from the northernmost part of the North Atlantic [Davies et al., 2001]. Deep-water production in the North Atlantic had likely already commenced in the early Oligocene [Via and Thomas, 2006], i.e., prior to the Fram Strait opening.

[4] On the basis of a conceptual two-layer model of the Arctic Ocean circulation in the early Miocene, Jakobsson et al. [2007] estimated the minimum width of the Fram Strait required for oxygenation of the deep water masses. They assumed that the oxygen level was primarily controlled by the turnover time of the basin, which was calculated from the net volume exchange in the Fram Strait. Furthermore, they suggested that a turnover time less than about 1000 years was required to prevent anoxic conditions. Based on this and the conceptual model, it was suggested that the transition to the oxygenated well-ventilated regime occurred when the Fram Strait reached a width of approximately $40-50 \mathrm{~km}$.

[5] The use of a bulk turnover time to infer oxygen concentrations, however, can under some circumstances be misleading. The turnover time is commonly defined as the time taken by a substance to fill a basin, or the time taken to renew the substance in a basin. One potential problem is that some water spends longer as well as shorter time in the basin than suggested by the turnover time [Bolin and Rodhe, 1973]. Ultimately, the age distribution is determined by the character of the circulation that renews the water in the basin. Another limitation is that the oxygen level is not only controlled by the turnover time; it is also affected by biogeochemical processes [e.g., Karlson et al., 2002].

[6] In the present paper, we use a three-dimensional ocean circulation model to analyze the sensitivity of the ventilation time in a semienclosed ocean basin to varying strait width, freshwater and surface wind stress. We relate our results to the Arctic Ocean's transition to a well-ventilated circulation regime as proposed by Jakobsson et al. [2007], and follow the suggestion that the ventilation of the subsurface waters in early Miocene Arctic was primarily accomplished by import of oxygenated Atlantic water through the Fram Strait, rather than by seasonal convection within the basin. It is assumed that subsurface oxygen content was directly related to the age of the water in the basin. Furthermore, how representative the turnover time is for the age distribution in an ocean basin such as the early Miocene Arctic Ocean is examined. This issue is also of interest for ventilation studies of other ocean basins, such as the Mediterranean, the Black Sea and the Baltic Sea. These have similar physiographic settings as the Arctic Ocean, with the circulation and bottom ventilation related to in/out flow of oxygenated water through a relatively narrow strait. In particular, we investigate under which conditions the turnover time is expected to give an upper bound on the mean age of the water in the basin.

[7] To examine these questions, we have conducted a series of simulations of the circulation in an idealized ocean basin using the Geophysical Fluid Dynamics Laboratory (GFDL) Modular Ocean Model (MOM4) with a prognostic 
passive age tracer. The age tracer allows a quantitative check on how well the turnover time captures the age distribution of the water in the basin. The ocean model was integrated using highly simplified bathymetry and forcing configurations, designed to reveal how factors such as strait width, freshwater supply and wind forcing affect the turnover time and the age distribution.

\section{Background}

[8] The Integrated Ocean Drilling Program (IODP) Expedition 302, a.k.a. the Arctic Coring Expedition (ACEX), drilled through a $428 \mathrm{~m}$ thick sediment sequence accumulated on the Lomonosov Ridge (Figure 1), close to the North Pole, encompassing the Arctic Ocean Cenozoic paleoceanographic evolution [Backman and Moran, 2008]. In the present climate, the deeper parts of the Arctic Ocean are well ventilated and oxygenated [Rudels, 1995; Tanhua et al., 2009]. In the Paleogene, on the other hand, the Lomonosov Ridge sediment sequence indicates that euxinic conditions, similar to those in the present Black Sea, frequently prevailed at the paleodepths of the ACEX coring sites [Stein et al., 2006, Sangiorgi et al., 2008]. Furthermore, the sediment sequence documents that a transition in the ventilation state of the Arctic Ocean occurred in the later part of the early Miocene, and that a fully ventilated oxygenated ocean phase was established $\sim 17.5$ Ma [Jakobsson et al., 2007] (Figure 2). The subunit $1 / 5$ consist a sequence of gray and black layers. The samples from gray layers have an anoxic character, while samples from dark layers show a euxinic character. These changes in the subunit $1 / 5$ reveal a transition from euxinic to oxic conditions. Also, the presence of similar foraminifer species in the ACEX core records and in the early Miocene samples from ODP Hole 909C in the Fram Strait and in the Norwegian-Greenland seas suggest the deep water connection between the Arctic and North Atlantic Oceans [Sangiorgi et al., 2008]. This is consistent with the tectonic evolution of the Arctic Ocean, which evolved from a land-locked basin with no significant connection to the World Ocean to a marginal sea with a communication with the North Atlantic through the Fram Strait [Vogt et al., 1979; Engen et al., 2008].

\section{Addressing Water Mass Age With Ocean Models}

[9] The age and the turnover time are different transport time scales used in studies for understanding the water transport properties. These time scales are differently defined in the literature, depending on the scientific problem addressed [Bolin and Rodhe, 1973; Andersson and Pucar, 1995; Döös et al., 2004; Monsen et al., 2002; England, 1995; Deleersnijder et al., 2001]. Zimmerman [1988] defined age as the time spent by a water parcel since entering an estuary through one of the boundaries. A similar definition is provided by Delhez and Deleersnijder [2002], who denote age as the "time elapsed since the parcel under consideration left the region in which its age is prescribed to zero." The concept of age in ocean modeling is mainly used for studying the ventilation rate of ocean basins and for inferring the circulation of shelf areas [e.g., Deleersnijder et al., 2001].
[10] Ocean General Circulation Models (OGCMs) are useful for studying transport processes. One approach for computing the tracer age is the Lagrangian dispersion technique, where Lagrangian trajectories are determined from the velocity fields computed by ocean models [Döös et al., 2004; Jönsson et al., 2004]. In these studies the tracers are advected by the three-dimensional model velocity fields, without diffusion. An advantage of this method is that the trajectories are computed offline; this reduces the computational expense for the OGCM integrations.

[11] Another approach is to integrate numerical ocean models with prognostic passive tracers, governed by the advection-diffusion equation, similarly as the active tracers (temperature and salt). This has been done in many earlier studies [Cox, 1989; Stocker et al., 1992; England, 1995; Hirst, 1999; Deleesnijder et al., 2001, 2002; Khatiwala et al., 2001, 2005; Delhez and Deleersnijder, 2002]. The approach we choose for the age tracer implementation in the present study is similar to the modeling study by England [1995]. To understand the transition of the Arctic Ocean to a fully ventilated circulation system, we investigate the relation between the turnover time and mean tracer age for different strait dimensions and forcing conditions.

\section{Model and Methodology}

[12] The present idealized model is designed to capture some general features of the Arctic Ocean during early Miocene (Figure 1b). The model basin geometry is illustrated in Figure 3. We model the "Arctic" (the northern basin) as a simple semienclosed basin that communicates with the "Atlantic" (the southern basin) through a strait with a sill, which represents the Fram Strait. The simple shape of the "Arctic" basin is motivated by the fact that the Bering and Nares Straits were closed and that there was no Barents Sea connection during the early Miocene (Figure 1b) [Torsvik et al., 2002]. There exists no detailed information on the regional Arctic climate in the early Miocene. However, due to its land-locked and polar location we anticipate as a first assumption that the Arctic Ocean received a net input of freshwater from rivers and precipitation similar to today. Further, we assume a qualitatively similar large-scale distribution of the surface wind field as today, with mainly cyclonic winds over the Arctic. We have furthermore chosen to neglect the influence of temperature differences on the density field, so density depends only on salinity. This rather drastic simplification is partly motivated by indications that the high latitudes were generally warmer and the equatorto-pole temperature gradient was smaller during the early Miocene [Zachos et al., 2001; Waddell and Moore, 2008]. Thus, it is conceivable that the temperature difference between the northern North Atlantic and the Arctic Ocean was smaller during this period, implying that the density field was primarily controlled by salinity. In fact, even the present-day density field in the Arctic Ocean is strongly shaped by salinity [Rudels, 1995].

\subsection{Ocean Model and Configurations}

[13] The ocean model used for this study is the Geophysical Fluid Dynamics Laboratory Modular Ocean Model 


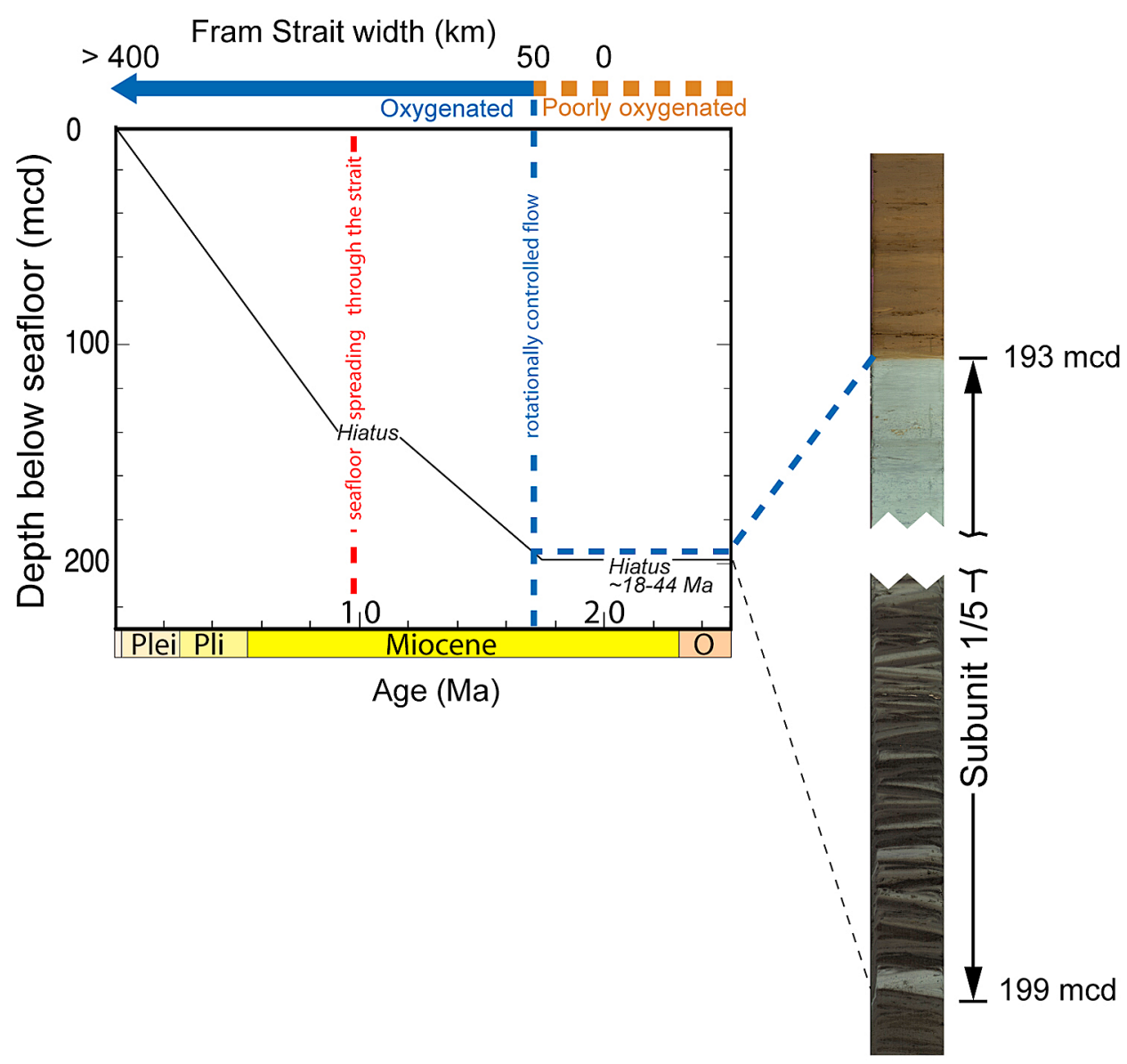

Figure 2. Age-depth plot for the Neogene section of the ACEX core retrieved from the Lomonosov Ridge in the central Arctic Ocean (core location is shown in Figure 1). The age control points are inferred from Backman et al. [2008]. The change in ventilation of the Arctic Ocean is documented in subunit 1/5, defined between about 193 and $199 \mathrm{~m}$ below the seafloor (meters composite depth (mcd)) [Backman et al., 2008]. The enlarged images show the lower and upper parts of subunit 1/5, respectively. The lower section consists of alternating gray and black layers with elevated total organic carbon (TOC) content in the black layers, representing euxinic conditions, and low TOC in the gray, suggesting more oxygenated conditions [Stein et al., 2006]. The gray/black transitional sediment sequence ends with a thicker gray layer that is overlaid by the brown sediments of subunit $1 / 4$. Benthic agglutinated foraminifera appear in the brown subunit 1/4 indicating an Arctic-North Atlantic connection [Kaminski et al., 2009], and the TOC is $<0.5 \%$, suggesting the establishment of oxygenated, "ventilated" conditions in the central Arctic Ocean [Jakobsson et al., 2007]. The conceptual model of Jakobsson et al. [2007] suggests that this change in ventilation state, dated to $17.5 \mathrm{Ma}$, occurred when the Fram Strait was on the order of 40-50 km wide, which allowed a rotationally controlled flow to be established. The first well-developed magnetic spreading anomaly through the Fram Strait is identified as Chron 5 (9.8 Ma), suggesting that seafloor spreading first at this time could begin developing the deep $(>2000 \mathrm{~m})$ portion of the Strait [Engen et al., 2008]. The narrowest part of the present Fram Strait exceeds $400 \mathrm{~km}$. Plei, Pleistocene; Pli, Pliocene; O, Oligocene.

Version 4 (MOM4p1) [Griffies, 2007]. MOM is a threedimensional $\mathrm{z}$ coordinate numerical representation of the hydrostatic primitive equations, employing the Boussinesq approximation and an explicit free surface. The model uses generalized orthogonal coordinates on an f plane, with $f=$ $1.4 \times 10^{-4} \mathrm{~s}^{-1}$. The temperature and salinity advection is handled through the second order moment scheme of Prather
[1986] with flux limiters [Merryfield and Holloway, 2003]. The age tracer is advected with a multidimensional piecewise parabolic scheme based on Colella and Woodward [1984]. The horizontal friction scheme is based on the shear-dependent Smagorinsky Laplacian viscosity according to Griffies and Hallberg [2000]. The model tracer fields and baroclinic velocity are time stepped with $3200 \mathrm{~s}$. The barotropic fields 


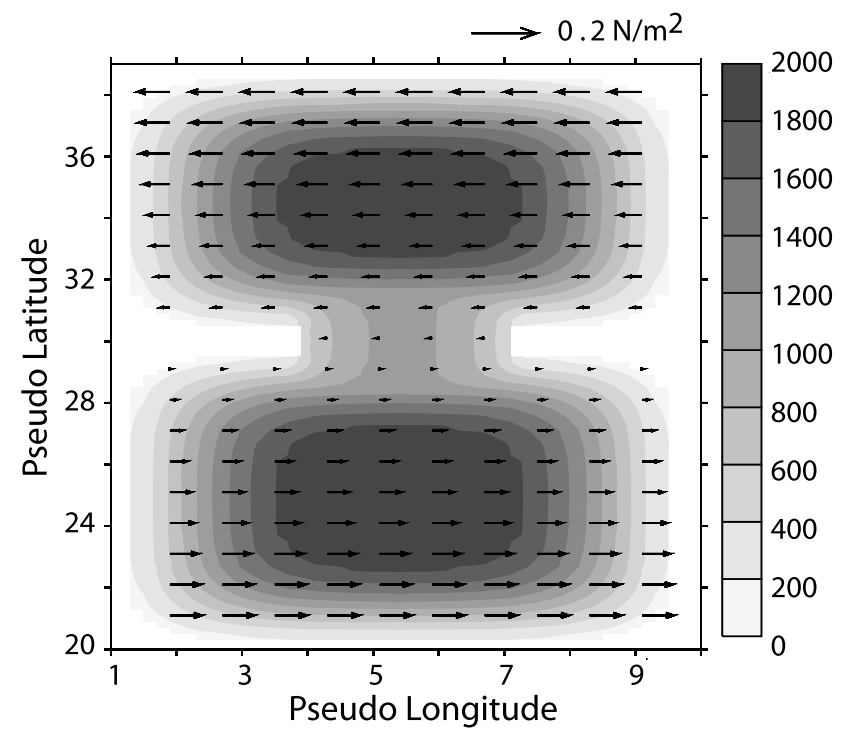

Figure 3. Ideal model bathymetry in the experiments with wider strait and the wind stress. Shading represents the depth of the basin. The sill depth is $1000 \mathrm{~m}$.

have a time step of $40 \mathrm{~s}$. The vertical mixing in the model is handled by the K Profile Parameterization Scheme [Large et al., 1994] having local and nonlocal mixing with a background diffusion of $0.30 \times 10^{-5} \mathrm{~m}^{2} \mathrm{~s}^{-1}$. The Gent and McWilliams [1990] scheme for parameterizing the subgridscale processes is turned off in our model experiments. In the model, density is given as a linear function of the salinity alone:

$$
\rho=\rho_{0}+\beta\left(S-S_{0}\right) .
$$

Here, $\rho_{0}=1035 \mathrm{~kg} \mathrm{~m}^{-3}$ is the background density, $\beta=$ $0.720 \mathrm{~kg} \mathrm{~m}^{-3} \mathrm{psu}^{-1}$ is the salinity contraction coefficient, $\mathrm{S}$ is the in situ salinity, and $\mathrm{S}_{0}=35 \mathrm{psu}$ is the reference salinity.

[14] The model topography consists of two basins connected with a strait over a sill (Figure 3). The model domain has the dimensions $9^{\circ}$ (x direction) and $19^{\circ}$ (y direction) with a uniform horizontal resolution of $0.2^{\circ} \times 0.2^{\circ}$. The basins have sloping bottom boundaries and reach a maximum depth of $2000 \mathrm{~m}$ at some distance from the coast. In most experiments the sill depth is $1000 \mathrm{~m}$, but in one experiment it is reduced to $250 \mathrm{~m}$. The vertical resolution is nonuniform, with 30 levels. The vertical grid distance stretches from $10 \mathrm{~m}$ at the surface to $100 \mathrm{~m}$ at $1000 \mathrm{~m}$, and $250 \mathrm{~m}$ at $2000 \mathrm{~m}$ depth.

[15] Three sets of experiments were performed with two different strait widths, $\sim 325 \mathrm{~km}$ and $\sim 96 \mathrm{~km}$. In our reference simulations with wide (Exp1) and narrow (Exp3) straits the ocean is initially at rest and isohaline, with a salinity of $35 \mathrm{psu}$. The model is forced by a constant input of freshwater along the boundaries in the northern basin. To avoid the direct influence of freshwater forcing in the strait, the freshwater flux is limited to the northern half of the basin. The salinity in the southern basin is relaxed toward 35 psu from the surface to the bottom in a relaxation zone extending 3 degrees from the southern boundary. In order to soften the restoring, the relaxation time decreases linearly from 10 days at the southern boundary to 160 days at the northern edge of the relaxation zone. The freshwater flux is either $0.16 \mathrm{~Sv}$ or $0.2 \mathrm{~Sv}\left(1 \mathrm{~Sv}=10^{6} \mathrm{~m}^{3} \mathrm{~s}^{-1}\right)$. (An additional experiment was also done with very weak freshwater flux, $0.05 \mathrm{~Sv}$, a wide strait and without wind; see section 5.4) In the first experiment (Exp1), with a strait width of $\sim 325 \mathrm{~km}$, the model is integrated with a freshwater flux of $0.16 \mathrm{~Sv}$ for 3300 years. The second experiment (Exp2) is a variant of Exp1, where after 700 years of Exp1, the freshwater flux is increased to $0.2 \mathrm{~Sv}$ and integrated for 3000 years. In the third experiment Exp1W, the model is forced by $0.16 \mathrm{~Sv}$ freshwater and a cyclonic zonal wind stress (with a maximum of $\pm 0.1 \mathrm{~N} \mathrm{~m}^{-2}$ at the northern and southern boundaries), and integrated for 2000 years from the initial conditions of Exp1 at the end of year 700 . The zonal wind stress $X$ is

$$
\mathrm{X}=\mathrm{B} \cos ((\mathrm{y} / \mathrm{L}) \pi) .
$$

Here, $B=0.1 \mathrm{~N} \mathrm{~m}^{-2}$ is the maximum value of wind stress, $L$ is the total length of the model domain, and $y$ is the distance from the southern boundary.

[16] Similar simulations were performed for a strait width of $\sim 96 \mathrm{~km}$, with the fresh water fluxes 0.16 Sv (Exp3), $0.2 \mathrm{~Sv}$ (Exp4), and 0.16 Sv and zonal wind stress (Exp3W). The different model configurations and forcings are presented briefly in Table 1 . The water flowing into the northern basin is considered as inflow and water flowing out of the northern basin is considered as outflow in our study.

[17] Even though our model configurations are highly idealized, the model bathymetry and surface boundary conditions are chosen with the early Miocene Arctic-North Atlantic Oceans in mind. While the evolutions of the width and depth of Fram Strait over the Miocene are largely unknown, we have chosen a strait for experiments Exp3, Exp4 and Exp3W that is wider than the minimum width of 40-50 km suggested by Jakobsson et al. [2007] for the onset of a rotationally controlled flow regime through Fram Strait. The freshwater flux and the cyclonic wind stress are chosen to resemble the present-day conditions in the Arctic Ocean. For computational reasons the basin area is only one tenth of the area of the Miocene Arctic Ocean; the implications of this are discussed in section 5.4.

\subsection{Age Tracer in the Model}

[18] The model was integrated with a prognostic passive age tracer. The ideal age is defined as the time elapsed since

Table 1. Model Experiments and Forcing Along With the Rossby Radius of Deformation at the Strait

\begin{tabular}{lcccc}
\hline & $\begin{array}{c}\text { Strait } \\
\text { Width } \\
(\mathrm{km})\end{array}$ & $\begin{array}{c}\text { Freshwater } \\
\text { Flux } \\
(\mathrm{Sv})\end{array}$ & $\begin{array}{c}\text { Wind } \\
\text { Stress } \\
\left(\mathrm{N} / \mathrm{m}^{2}\right)\end{array}$ & $\begin{array}{c}\text { Rossby } \\
\text { Radius } \\
(\mathrm{km})\end{array}$ \\
\hline Exp1 & 325 & 0.16 & Nil & 7.7 \\
Exp2 & 325 & 0.20 & Nil & 8.2 \\
Exp1W & 325 & 0.16 & 0.1 & 7.7 \\
Exp3 & 96 & 0.16 & Nil & 7.6 \\
Exp4 & 96 & 0.20 & Nil & 8.0 \\
Exp3W & 96 & 0.16 & 0.1 & 9.8 \\
\hline
\end{tabular}


a water parcel was last in contact with a designated region in the hypothetical situation where diffusion has no effects. Note that this definition is different than that of Khatiwala et al. [2001], who include diffusive effects in the ideal tracer age. In our study, the tracer age $(\tau)$ includes the diffusive effects, and is defined by the relation [e.g., England, 1995]

$$
\frac{\partial \tau}{\partial t}=\Re(\tau)+1
$$

Here, $\Re$ is the linear transport operator including advection and diffusion. The tracer age is taken to be zero everywhere at the beginning of model integration. In the southern basin, the tracer age is restored to zero at every model time step, whereas it is allowed to evolve in the northern basin. Therefore, the tracer age essentially represents the time elapsed since the water parcel left the southern basin. It should be noted that, differently from many previous studies [e.g., England, 1995], the age of surface water in the northern basin is not restored to zero in our experiments. The continuous increase of the tracer age in the northern basin is limited only by the inflow of zero-age water from the south.

\subsection{Age Distributions}

[19] The distribution of age in the northern basin and in the water flowing out through the strait is succinctly described by the frequency functions introduced by Bolin and Rodhe [1973]. Each water particle in the basin is characterized by a specific age, $\tau$, and the age frequency function $\chi$ is defined as [Bolin and Rodhe, 1973]

$$
\chi=\frac{1}{V_{0}} \frac{d V(\tau)}{d \tau} .
$$

Here, $V_{0}$ is the total volume of water in the northern basin, and $V(\tau)$ is the volume of water that is younger than $\tau$. The function $\chi$ describes the age distribution in the northern basin, and $\int_{0}^{\infty} \chi d \tau=1$. From the definition of $\chi$, the mean age of the water in the northern basin $\left(\tau_{\text {mean }}\right)$ is given by

$$
\tau_{\text {mean }}=\int_{0}^{\infty} \tau \chi d \tau .
$$

Furthermore, the age distribution $\varphi$ of the water particles leaving the northern basin is defined as

$$
\varphi=\frac{1}{F_{0}} \frac{d F(\tau)}{d \tau}
$$

Here, $F_{0}$ is the total volume flowing out of the northern basin per unit time. $F(\tau)$ is known as the transit time function, and is defined as the outflowing volume (per unit time) of water younger than $\tau$. Thus, $\varphi$ describes the age distribution of the outflowing water, and $\int_{0}^{\infty} \varphi d \tau=1$. In the absence of diffusion, i.e., in case of ideal age, the rate of change of $\chi$ is governed by

$$
\frac{\partial \chi}{\partial t}+\frac{\partial \chi}{\partial \tau}=-\frac{F_{0}}{V_{o}} \varphi
$$

Here, the second term on the left-hand side represents the translation of the age distributions toward larger $\tau$, i.e., the steady increase in age, and $-\varphi$ represents the export of water with the age $\tau$.

[20] In steady state, as considered in the present paper, equation (4) reduces to [see also Bolin and Rodhe, 1973]

$$
\frac{d \chi}{d \tau}=-\frac{F_{0}}{V_{0}} \varphi
$$

Since $\varphi \geq 0, \chi$ decreases with increasing age. Furthermore, integrating equation (5) we obtain $\chi_{(\tau=0)}=F_{0} / V_{0}$, which equals the inverse of the turnover time, as defined below.

\subsection{Turnover Time}

[21] The turnover time $\left(\tau_{0}\right)$ is the simplest and most usual method to estimate the water mass transport time from a basin. It is defined as the ratio of total volume of water $V_{0}$ to the total outflow $F_{0}$ from the basin:

$$
\tau_{0}=\frac{V_{0}}{F_{0}}
$$

The turnover time is often referred to as the flushing time or the residence time in water mass transport studies [e.g., Deleersnijder et al., 2001]. This quantity is a bulk parameter that describes the general characteristics of water mass exchange.

\section{Results}

[22] An important feature of the present experiments is that the entire northern basin becomes stably stratified, although the freshwater input occurs only along the coast. Since the deeper parts of the northern basin has salinity close to 35 (not shown), the stable stratification can be inferred from the surface salinity distributions shown in Figure 4. In the model, baroclinic eddies contribute to the transport of low-salinity water from the boundary to the central basin, where lateral eddy transport and vertical diffusion jointly shape the stratification [e.g., Karsten et al., 2002]. In fact, a pronounced time-dependent eddy circulation arises in all simulations (not shown). Inspections of the salinity field show a shallow halocline in the northern basin, which separates a low-salinity near-surface layer from deeper more saline waters that are imported from the southern basin. In all experiments the upper low-salinity layer, which reaches a depth of about $200 \mathrm{~m}$, is shallower than the sill depth, which is $1000 \mathrm{~m}$.

[23] In the absence of wind forcing, the surface circulation tends to be anticyclonic in both basins (Figures 4a and 4b). In particular, the low-salinity water that exits from the northern basin tends to follow the eastern boundary southward. This can be contrasted with the present-day Fram Strait region, where the low-salinity water follows the western boundary southward in the East Greenland Current [e.g., Rudels, 1995; Nilsson et al., 2008]. By adding cyclonic wind forcing, however, the surface outflow from the northern basin is shifted to the western boundary (Figure 4c). Thus, in the present model, the cyclonic wind stress gives rise to a surface circulation in the strait region, which qualitatively resembles 
(a)
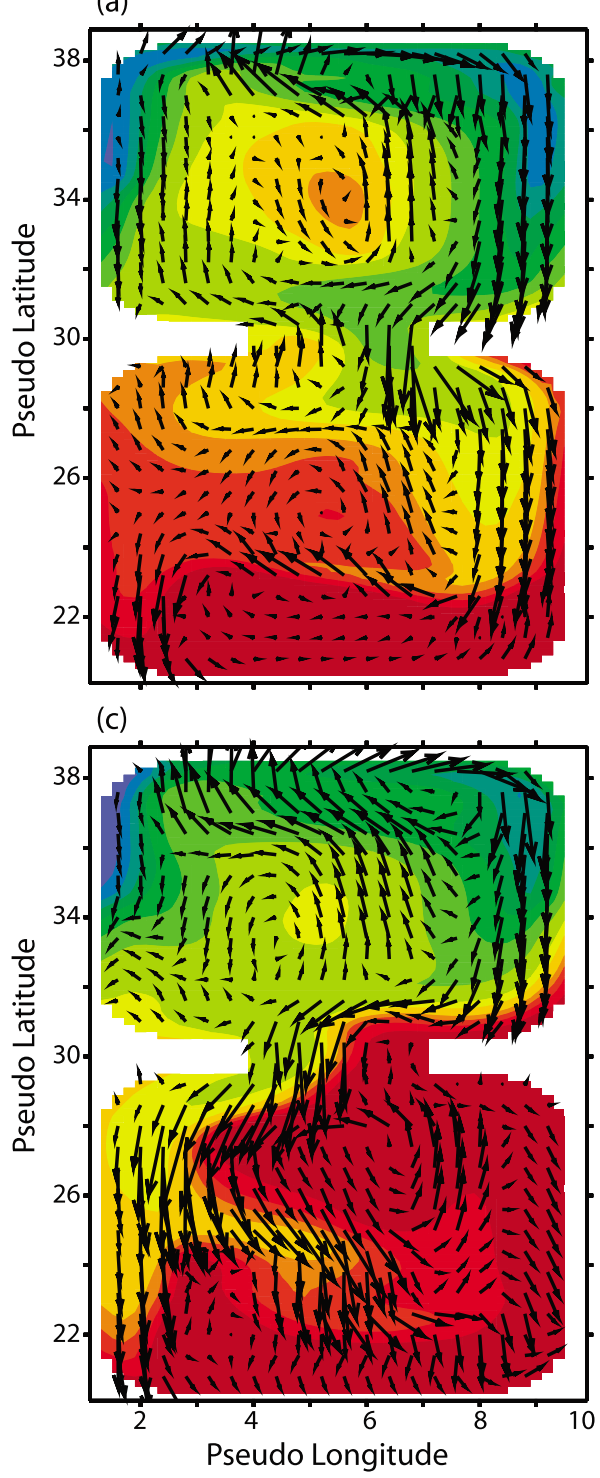

(b)

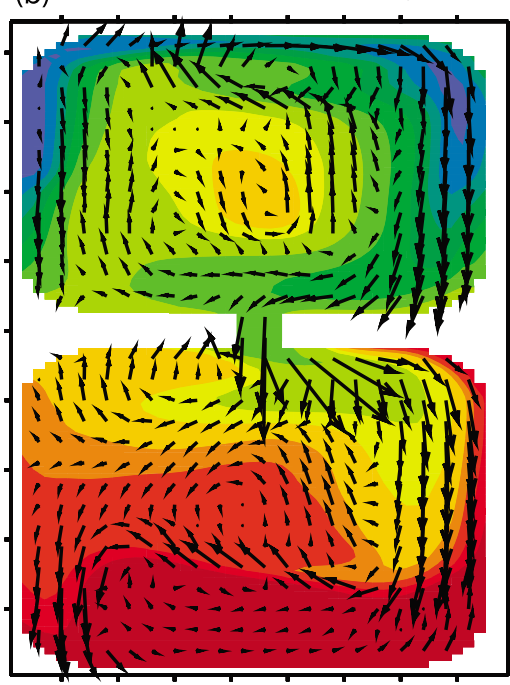

(d)

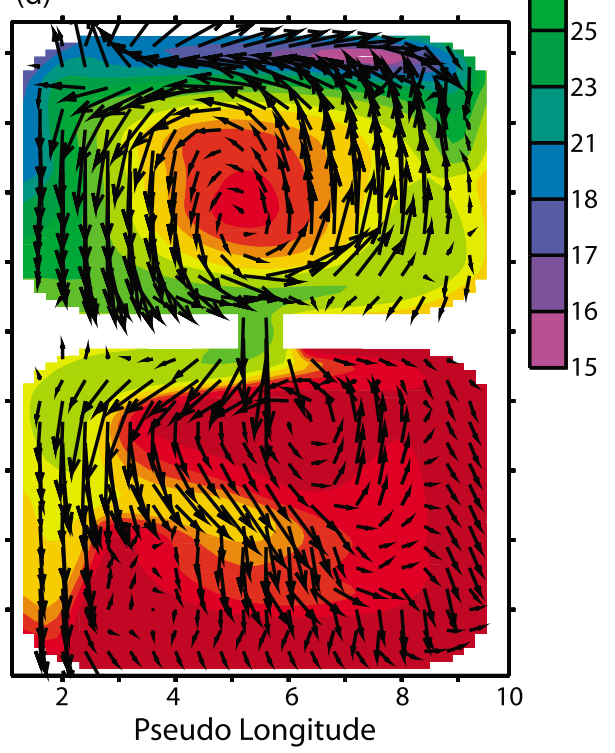

Figure 4. The time-mean sea surface salinity (in psu) overlaid by the surface current vectors (in $\mathrm{m} / \mathrm{s}$ ) for the experiments (a) Exp1, (b) Exp3, (c) Exp1W, and (d) Exp3W. The number of longitudinal velocity grid points in the strait is 16 and 4 for the wide and narrow strait widths, respectively. Every second vector in the $x$ direction and every third vector in the $y$ direction are shown.

that in the present-day Fram Strait. However, note that there is no analog of the northward flow of intermediate Atlantic water in the present model where the density depends only on salinity.

[24] There is an important difference in the exchange flow patterns between the experiments with wide and narrow straits. In the narrow-strait experiments, the direction of the flow does not change across the strait. There is outflow near the surface and inflow below. In the cases with a wide strait, on the other hand, the flow direction changes across the strait. In the upper layer, there is southward flow in the eastern part of the strait and northward flow in the western part in the absence of wind stress. In the deeper parts of the strait the flow is in the opposite direction to the surface flow.
Accordingly, there is a horizontal exchange flow component in the wide-strait experiments that is absent in the narrowstrait experiments. For the cases with wide straits and without wind stress, relatively saline water from the southern basin intrudes into the northern basin along the western part of the strait. Detailed analysis of instantaneous current fields reveal that this water turns counterclockwise and recirculates in the western part of the strait. Recirculation in the strait region is also present in the time-mean circulation. In general, the total outflow is about twice as strong in the wide-strait experiments as in the narrow-strait ones. Also in the presence of wind forcing, the exchange flow is essentially horizontally unidirectional in the narrow-strait experiments (Figure 4d). 
(a)

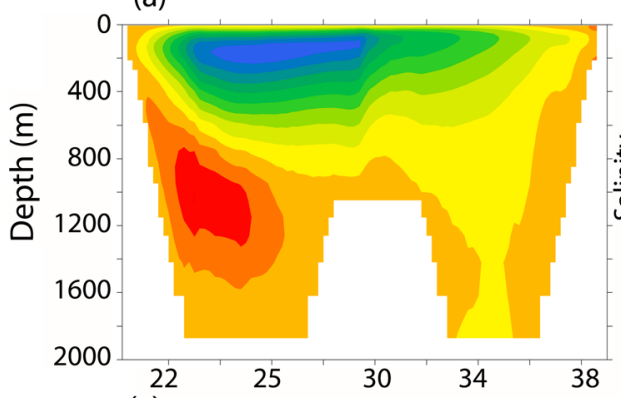

(b)

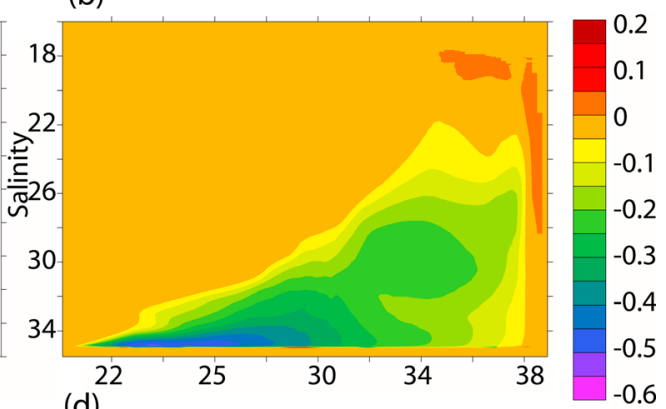

(d)

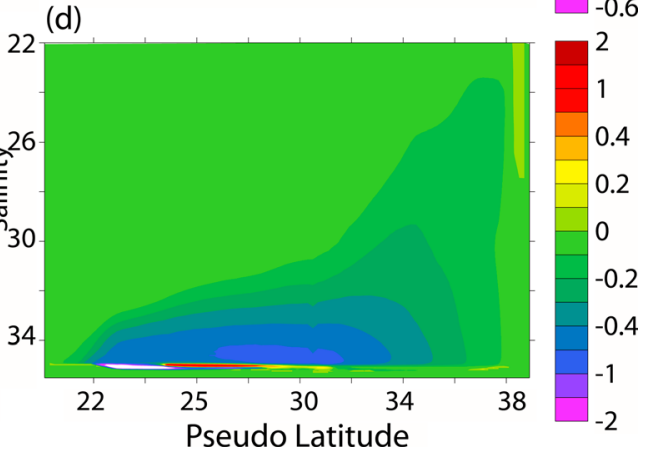

Figure 5. The meridional overturning stream function (in Sv) computed as a function of (a and c) depth or (b and d) salinity. The strait width is $325 \mathrm{~km}$ in all experiments. Figures $5 \mathrm{a}$ and $5 \mathrm{~b}$ are for the experiment without wind stress (Exp1), and Figures $5 \mathrm{c}$ and $5 \mathrm{~d}$ are for the experiment with wind stress (Exp1W). Contours with negative values represent counterclockwise circulation cells, and positive values represent clockwise circulation cells. The shading scale is different in Figures 5c and 5d.

[25] For narrow ocean channels, the effects of Earth's rotation on the exchange flow are insignificant and the flow will be controlled by the hydraulic dynamics (i.e., only by the density gradient between the basins). The minimum width of the strait at which the rotational effects become as important as those of density (or buoyancy) effects is known as the internal Rossby radius of deformation [Gill, 1982]. For a twolayer density structure, where the deep layer is much thicker than the upper layer, it is defined by $\mathrm{R}=\left(\mathrm{g} \mathrm{H} \Delta \rho / \rho_{0}\right)^{1 / 2} f^{-1}$, where $\Delta \rho / \rho_{0}$ is the relative density difference between the layers, and $H$ is the thickness of the upper layer. The unidirectional flow pattern in the present narrow-strait experiments is obtained when the strait is about 10 times wider than the internal Rossby radius, which is on the order of $10 \mathrm{~km}$ (Table 1). Accordingly, the transition to unidirectional strait flow in the present experiments occurs well before the flow becomes hydraulically controlled, which only occurs when the strait width is comparable to the Rossby radius [e.g., Pratt and Spall, 2008].

[26] In the present experiments, we believe that the transition to unidirectional flow when the strait is narrowed relates to the following physics. To begin with, the frontal zone between the outflow and inflow in the wide-strait experiments is about $100 \mathrm{~km}$ wide. The fact that this is much larger than the Rossby radius could be caused by baroclinc eddies, which strive to flatten isopycnal surfaces [e.g., Haine and Marshall, 1998; Held, 1999]. It could also be caused by the fact that the boundary current is anticyclonic. The study of Nøst et al. [2008] shows that barotropic anticyclonic flows that follow the depth contours are generally unstable, in contrast to the stable cyclonic flows. (An example of stable cyclonic boundary flows is the East Greenland Current). Rather than following depth contours, anticyclonic flows meander and become time dependent, which might make the outflow broader than the Rossby radius.

[27] Finally, it should be noted that there are only four velocity (five salinity) grid points across the narrow strait, and that the horizontal grid spacing is about twice as large as the Rossby radius. Thus, the transition to unidirectional currents for a strait of about $100 \mathrm{~km}$ width $(96 \mathrm{~km})$ could also be caused by the numerical resolution.

[28] The flow in our idealized ocean basin with sloping boundaries has many dynamical similarities with the flows studied by Spall [2004], Walin et al. [2004] and Iovino et al. [2008]. An important common feature among these studies and our experiments is that strong barotropic currents generally develop on the depth contours above the sill. These barotropic currents, which do not require wind forcing, arise if the bottom density varies along the depth contours [Walin et al., 2004; Nilsson et al., 2005]. In the present experiments without wind forcing, these barotropic slope currents shape the flow field, a feature that is imprinted on the salinity field as well as on the tracer age.

\subsection{Meridional Circulation}

[29] As a typical representation of simulations with and without wind forcing, Figure 5 shows the meridional over- 

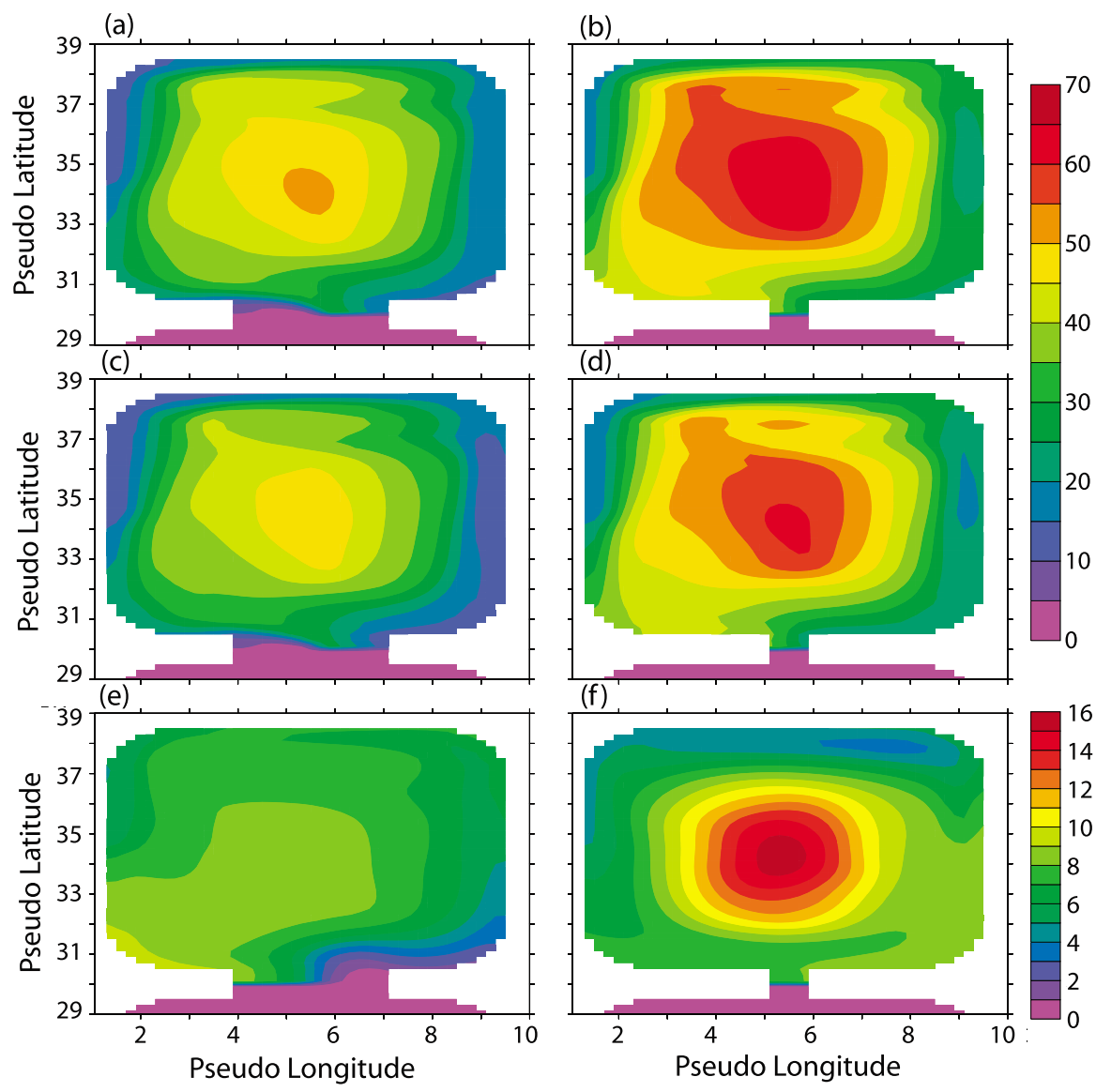

Figure 6. The surface tracer age in the northern basin for model experiments with strait width (left) $325 \mathrm{~km}$ and (right) $96 \mathrm{~km}$. The plots represent (a) Exp1, (b) Exp3, (c) Exp2, (d) Exp4, (e) Exp1w, and (f) Exp3w. The shading indicates the tracer age in years. The shading scale is different in Figures 6e and $6 \mathrm{f}$.

turning stream functions in latitude-depth and latitudesalinity coordinates for Exp1 and Exp1W. The overturning in latitude-depth coordinates consists of two cells with circulation in counterclockwise and clockwise directions. There is outflow of water from the northern basin in the upper levels and inflow in the lower levels.

[30] Since the density in the model depends only on salinity, the circulation is expected to largely follow isohaline surfaces. Thus, the overturning circulation in latitude-salinity coordinates is generally more useful for understanding the meridional circulation component that is associated with density change, i.e., water mass transformation. Details about how to calculate this stream function in latitude-salinity coordinates are given by Döös and Webb [1994] and by Döös et al. [2008]. It is characterized by a counterclockwise circulation cell, indicating southward flow of water with lower salinity. The recirculation in the southern basin, visible in latitude-depth coordinates, almost disappears when the zonal integration is performed on isohaline surfaces (Figure 5).

\subsection{Tracer Age}

[31] Figure 6 shows the tracer age in the surface layer of the northern basin, averaged over the last 100 years in the simulations. The horizontal distribution of the tracer age mirrors the topography, which reflects the presence of barotropic along-isobath currents that arise from bottom density variations and wind forcing [Walin et al., 2004; Nilsson et al., 2005]. Due to these slope currents, the water near the coasts is well ventilated and the tracer age is consequently low near the boundaries. The oldest surface water is encountered in the center of the basin.

[32] The surface tracer age increases when the strait width is decreased, whereas the increase of the surface fresh water flux leads only to a marginal reduction in the surface tracer age. A striking feature is that the introduction of the cyclonic wind stress substantially decreases the tracer age in the simulations with wide as well as with narrow straits. The surface tracer age is reduced by about $75 \%$ in the wind-forced experiments, indicating enhanced exchange through the strait.

[33] The vertical variation of the horizontally averaged tracer age and the maximum tracer age in the northern basin is drawn in Figure 7. It shows that the youngest water is in the uppermost $400 \mathrm{~m}$. This is the depth region with the strongest overturning circulation, as seen in Figure 5a. Below this region the horizontally averaged age increases almost linearly with depth in the experiments without wind forcing. 

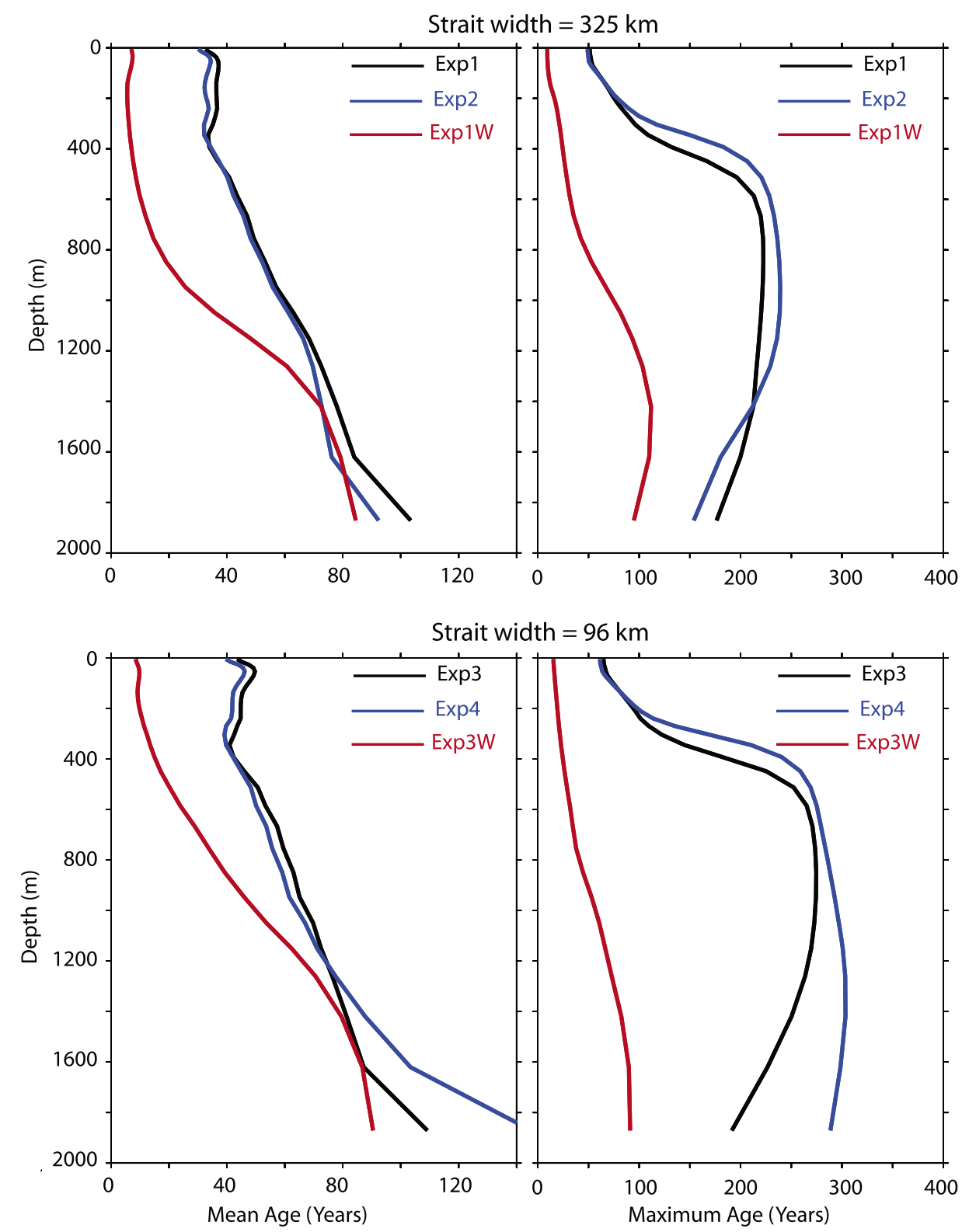

Figure 7. Vertical variation of tracer age in the northern basin. (top) The model with strait width $325 \mathrm{~km}$ and (bottom) the model with strait width $96 \mathrm{~km}$. Figure 7 (left) represents the horizontal mean age, and Figure 7 (right) is for the horizontal maximum age. The $x$ axis scales are different for Figures 7 (left) and 7 (right). Note that the experiments have a sill depth of $1000 \mathrm{~m}$ in the strait.

However, the vertical variation is not so organized for the horizontal maximum tracer age. For neither of the model strait widths does the increase of fresh water flux from 0.16 to $0.2 \mathrm{~Sv}$ make a significant difference on the mean and maximum ages. Another interesting feature is that the oldest water in the basin is not encountered at the bottom of the basin; it is rather located somewhere at middepth. This is primarily due to the supply of dense inflowing water with low tracer age to the regions below the sill, and to the upwelling in the central part of the northern basin driven by the interaction between the cyclonic flow and the bottom friction. In contrast, the horizontal mean of the tracer age has its maximum value at the bottom of the basin. This implies that the horizontal variations of tracer age decrease with depth.

[34] One important result is the considerable reduction of tracer age in the model experiment with wind forcing. Even though both maximum and mean ages in the basin show this reduction, the difference is more prominent in the maximum age, which is reduced by about $60 \%$. The difference in maximum tracer age between wind-forced and no-wind experiments increases with depth and is at its maximum at 


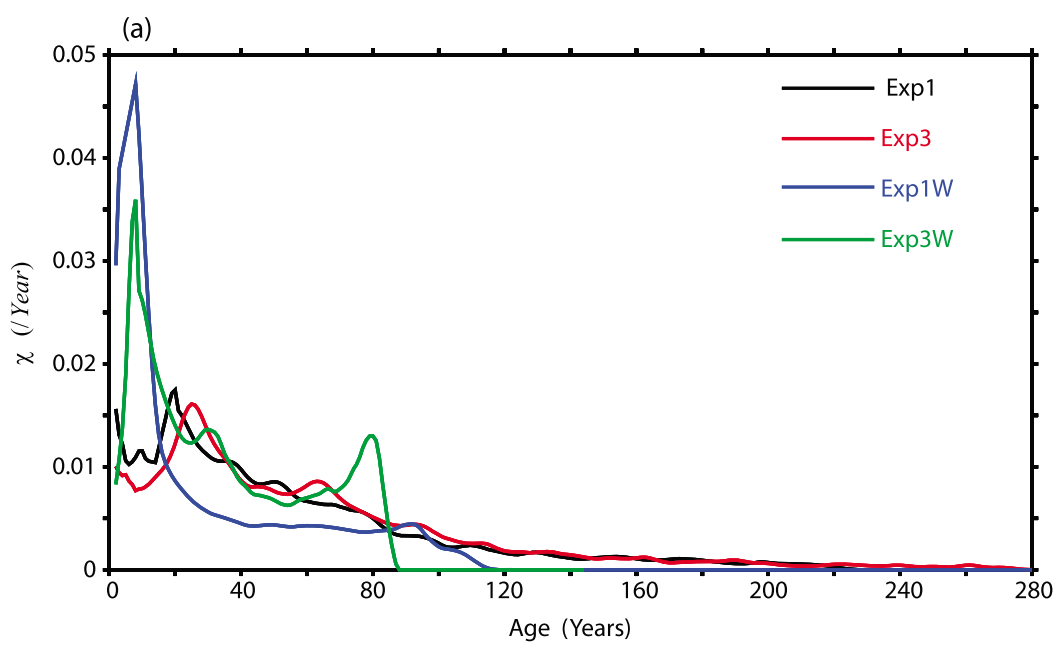

(b)

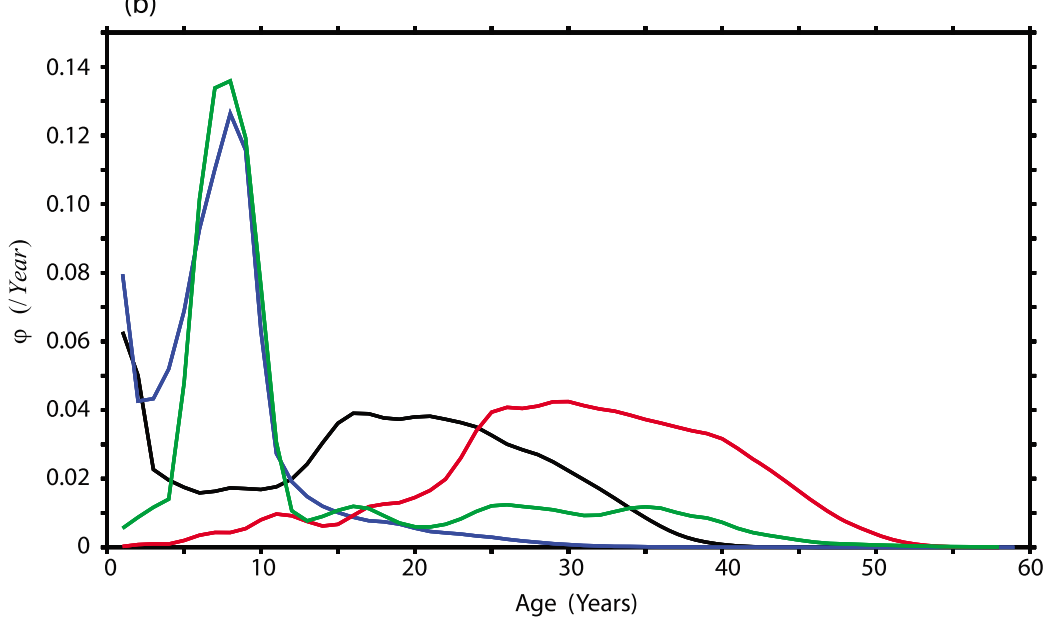

Figure 8. The frequency functions of (a) age distribution of particles in the northern basin and (b) age distribution of particles leaving this basin for the experiments Exp1, Exp1W, Exp3, and Exp3W. The legends shown in Figures 8a also apply to Figure 8b. The axes' scales are different in Figure 8b.

400-1000 m. Below the sill depth $(1000 \mathrm{~m})$ the difference between mean ages, with and without wind forcing, gradually decreases, and below $\sim 1400 \mathrm{~m}$ the tracer ages in both the experiments become comparable. The mean tracer age of the entire northern basin in the simulations with wind forcing is reduced by about $50 \%$ compared to simulations without wind stress.

[35] In the simulations with only freshwater forcing (Exp1, Exp2, Exp3 and Exp4), the mean and maximum tracer ages are nearly constant from the surface to a depth of about $300 \mathrm{~m}$, roughly coinciding with the pycnocline. Interestingly, with the incorporation of wind forcing, the depth over which tracer age is constant increases to a depth of about $1000 \mathrm{~m}$, which coincides roughly with the sill depth in the strait.

[36] To examine the influence of the sill depth on the ventilation process, we carried out an additional experiment with the narrow strait width of $\sim 96 \mathrm{~km}$, where the sill depth was reduced to $250 \mathrm{~m}$ (it was $1000 \mathrm{~m}$ in all other experiments). In this simulation, which has no wind forcing, the upper low- salinity layer in the northern basin has a depth of about $200 \mathrm{~m}$ and is thus shallower than the sill. Although the sill depth is reduced by a factor of 4 , the tracer age does not change significantly. The maximum tracer age increases by only about $8 \%$, and the mean tracer age even less. In agreement with theoretical models of strait flows [Stigebrandt, 1981; Pratt and Spall, 2008], this experiment suggests that the exchange flow is essentially independent of the sill depth as long as the upper layer is shallower than the sill depth. However, the influence of sill depth is expected to become strong in the over-mixed regime, where the upper layer extends below the sill. It may also be stronger for a wind-forced flow.

[37] The frequency distribution (or spectrum) $\chi$ of the age tracer in the northern basin is shown in Figure 8a for the experiments Exp1, Exp1W, Exp3 and Exp3W. The frequency distribution is computed from monthly mean fields of the simulated tracer age and averaged over the last few hundred years. Generally, $\chi$ peaks at young age and decreases with increasing age. In the experiments with wind forcing, 


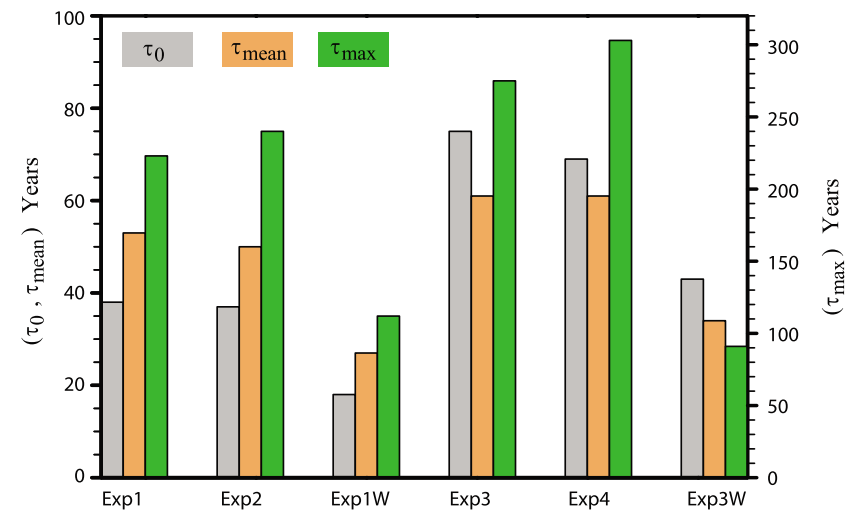

Figure 9. The turnover time $\left(\tau_{0}\right)$, mean tracer age $\left(\tau_{\text {mean }}\right)$, and maximum tracer age $\left(\tau_{\max }\right)$ estimated for different model experiments. The left $y$ axis represents the turnover time and mean tracer age. The maximum tracer age is represented by the right $y$ axis.

the age spectra are sharply peaked toward younger age. In the no-wind experiments, on the other hand, the age spectra tend more slowly toward zero, having long tails extending to high ages. In the ideal case, corresponding to a nondiffusive age tracer, the age spectrum should decrease monotonically in steady state (equation (5)). In the present numerical experiments, however, there is some diffusive mixing. As a result, local maxima can arise in the age spectra. Strong mixing in the basin would tend to peak the age spectrum around the mean tracer age. Thus, the localized maxima seen in Figure 8a are due to diffusive mixing, which implies that equation (5) holds only in an approximate sense.

[38] One important difference in the ventilation characteristics between the model experiments with wide and narrow straits is revealed in the frequency distribution $\varphi$ for the transit time (Figure $8 \mathrm{~b}$ ). With a narrower strait, the peak of the transit time spectrum shifts toward larger ages. This implies that the water leaving the basin in the narrow-strait experiments tends to be older. In fact, the narrow and widestrait experiments represent two prototype reservoirs with different ventilation characteristics that were discussed by Bolin and Rodhe [1973]. In the narrow-strait case, the mean tracer age is smaller than the turnover time (Figure 9). This situation occurs when there is predominantly a "pipe-like" flow through the basin; the water becomes gradually older and it is the oldest water that leaves the basin. In the widestrait case, on the other hand, the mean tracer age is larger than the turnover time. This situation occurs when the bulk of inflow exits relatively rapidly, but a smaller fraction remains long enough to make the mean tracer age large [Bolin and Rodhe, 1973]. In the present wide-strait experiments, it is the recirculation in the strait region that lowers the turnover time. In Figure $8 \mathrm{~b}$, the recirculation in the wide-strait experiments is manifested by the high values of the transit time spectra at very young ages ( $\tau<5$ years). Similar to the spectrum of the age distribution in the basin, the transit time spectrum $\varphi$ shifts toward younger ages in the wind-forced experiments. Note that in the wind-forced experiment with a narrow strait $(\operatorname{Exp} 3 \mathrm{~W})$, the transit time spectrum extends toward large ages.

[39] Since the age tracer is restored to zero in the region south of the middle of the strait, there may be steep meridional gradients in tracer age there, and therefore a strong diffusive flux. The transit time spectra were therefore not computed exactly in the middle of the strait, but rather in the first grid point north of the middle of the strait. We have also computed $\varphi$ in other zonal planes north of the strait, but found that it is not very sensitive to the distance from the strait. In general, however, diffusive mixing causes deviations from the idealcase relation between the age considered by Bolin and Rodhe [1973], and given by equation (5).

\subsection{Turnover Time}

[40] The turnover time defined in section 4.4 and the mean and maximum tracer ages ( $\left.\tau_{\text {mean }}\right)$ are plotted in Figure 9 . As pointed out in connection with the age tracer distribution, the turnover time is always less than the mean tracer age $\left(\tau_{0}<\tau_{\text {mean }}\right)$ in the experiments with the wider strait, whereas in the experiments with the narrower strait, the turnover time is larger than the mean age $\left(\tau_{0}>\tau_{\text {mean }}\right)$. It is interesting to note that this feature holds for the experiment with as well as without wind forcing. The reason is that in the wide-strait experiments, the inflowing water follows different trajectories with shorter as well as longer transit times. Roughly, the short trajectories are related to the recirculation in the strait region (Figure 4), which results in a relatively low turnover time. As noted earlier, the strait widths in our simulations are not narrow enough to produce hydraulically controlled flows. However, the small strait experiments are narrow enough to make the flow across the strait unidirectional. This causes the exchange flow to be more "pipe-like," in the sense that the water particles tend to traverse the bulk of the basin before exiting. As pointed out by Bolin and Rodhe [1973], the turnover time tends to be larger than mean tracer age in reservoirs with such a flow pattern.

\subsection{Sensitivity of Ventilation Time to Varying Wind Stress and Freshwater Flux}

[41] Here, we consider qualitatively how variations of wind stress and freshwater supply affect the turnover time in the basin. To this end, we recapitulate some results with relevance for the circulation in the paleo Arctic Ocean. To begin with, it is well documented that the large-scale circulation in the present-day Arctic Ocean and Nordic Seas largely follows the depth contours [e.g., Rudels, 1995; Nøst and Isachsen, 2003]. Essentially, the reason is that for geostrophic flows, the bottom currents tend to follow the contours of constant $f / H$. In the Arctic Ocean, these contours are essentially given by the topography of the basin. For steady state geostropic flows, the integrated surface wind stress $(X)$ around closed depth contours must balance the integrated bottom stress [Nøst and Isachsen, 2003; Nilsson et al., 2005], which roughly implies that

$$
X \propto \rho_{w} C_{D} U_{b}^{2}
$$


Here, $\rho_{w}$ is the density of water, $C_{D}$ is the drag coefficient, typically of the order $10^{-3}$, and $U_{b}$ is the bottom velocity. Accordingly, the wind stress and the along-slope bottom velocity are approximately related as $U_{b} \propto \sqrt{X}$. The winddriven barotropic flow along the depth contours is thus related to the wind stress according to

$$
\psi_{\text {barotropic }} \propto \sqrt{X} \text {. }
$$

While the along-isobath barotropic flow is proportional to the square root of the wind stress, the Ekman and Sverdrup transports are proportional to the wind stress. Accordingly, when the along-isobath flow dominates the barotropic circulation, as in the present-day Arctic Ocean, the dependence of the strength of this flow on the wind stress is fairly weak. Taking a surface wind stress of $0.1 \mathrm{Nm}^{-2}$, a typical value for present-day Arctic [Risien and Chelton, 2006], equation (7) predicts a bottom velocity on the order of $0.1 \mathrm{~m} \mathrm{~s}^{-1}$. This suggests that for a surface wind stress of $\sim 0.1 \mathrm{Nm}^{-2}$, the barotropic flow should dominates the exchange between the basins in our simulations (Figure 4).

[42] The comparison between the tracer age and the turnover time shows that the reduction in tracer age due to the wind stress is captured reasonably well by the turnover time for experiments with wide as well as narrow strait widths. In the present study, no additional model experiments were performed to investigate the sensitivity of ventilation time to varying surface wind stress. Due to the square root dependence noted above, an increase in the wind stress by a factor two will increase the transport by only $40 \%$. Presumably, there will be a corresponding reduction in the turnover time. But from our earlier analysis, it is not certain that there will be a precise reduction in the tracer age equivalent to the decrease in turnover time.

[43] In the absence of wind forcing, the depth of the halocline is primarily controlled by a balance between the vertical turbulent mixing and the geostrophic outflow of low-salinity water through the strait. This implies that the flow is approximately described by the classical thermocline scaling [e.g., Welander, 1971; Nilsson and Walin, 2001]. Here, we use a two-layer description of the flow, where the upper layer represents the halocline [Jakobsson et al., 2007; Nilsson and Walin, 2010]. If the outflow from the basin is large compared to the freshwater supply $F$, the volume- and salinity-conservation equations can be simplified. The conservation of volume in the upper layer is, at the leading order, given by

$$
A \frac{d H}{d t}=-\psi_{G}+\psi_{D}
$$

Here $A$ is the basin area, $H$ is the halocline depth, $\psi_{G}$ is the geostrophic outflow, and $\psi_{D}$ is the mixing-driven upwelling. Furthermore, the conservation of salinity is, at the leading order, given by

$$
A H \frac{d \Delta S}{d t}=-\Delta S \psi_{D}+S_{0} F
$$

Here, $\Delta S$ is the salinity difference between the lower and upper layer and $S_{0}$ is a constant mean salinity. The geostrophic outflow is represented as

$$
\psi_{G}=\frac{g \beta \Delta S H^{2}}{2 f \rho_{0}},
$$

where $g$ is the acceleration of gravity and $f$ is the Coriolis parameter. For the mixing-driven upwelling, we first assume that the turbulent diffusivity $k$ is constant, which suggests the following representation [e.g., Welander, 1971; Nilsson and Walin, 2001]

$$
\psi_{D}=\frac{k A}{H}
$$

In a steady state, $\psi_{G}=\psi_{D}=\psi$, and the salinity balance (10) simplifies to $\Delta S \psi=S_{0} F$. Together with equation (11) this determines the product $\Delta S H$, and thereby the baroclinic Rossby radius $\mathrm{R}=(\mathrm{g} \beta \Delta \mathrm{SH})^{1 / 2} \mathrm{f}^{-1}$, which can be written as

$$
R=\left(\frac{2 g \beta S_{0} F}{f^{3}}\right)^{1 / 4}
$$

Thus, in this two-layer model, the Rossby radius is independent of the basin area and the vertical mixing, and depends only weakly on the freshwater supply.

[44] By assuming a steady state and using equations (9) (12), we find after some manipulations the following relations:

$$
\begin{gathered}
\mathrm{H} \propto(\mathrm{kA})^{1 / 2} \mathrm{~F}^{-1 / 4}, \\
\Delta \mathrm{S} \propto(\mathrm{kA})^{-1 / 2} \mathrm{~F}^{3 / 4}, \\
\psi \propto(\mathrm{kA})^{1 / 2} \mathrm{~F}^{1 / 4} .
\end{gathered}
$$

Thus, the volume transport is a very weak function of the freshwater flux. To increase the volume transport by a factor 2, the freshwater flux has to be increased by a factor 16 according to equation (16). To examine this, we performed an additional wide-strait experiment without wind forcing, where the freshwater supply was lowered to $0.05 \mathrm{~Sv}$. The suite of experiments with the freshwater supplies $0.05,0.16$ and $0.2 \mathrm{~Sv}$ yield the turnover times 49,38 , and 37 years, respectively. This is roughly consistent with equation (16).

[45] We will now use these results to discuss how the flow properties, in particular the turnover time, depend on the volume of the basin for a fixed strait geometry. The area of our idealized basin is about ten times smaller than the Miocene Arctic Ocean, whereas the depths and strait widths are roughly comparable [Jakobsson et al., 2007]. (The use of a smaller basin in the numerical experiments is dictated by the computational cost, which would be roughly 100 times 
larger for the realistic basin area.) For a purely wind-driven exchange flow, equation (8) suggests that if the wind stress is constant, then the exchange flow is also constant. In this case, the turnover time is proportional to the basin area, i.e., $\tau_{0}=V_{0} / \psi \propto A$. If on the other hand, the circulation is buoyancy driven, equation (16) suggests that $\tau_{0} \alpha A^{1 / 2}$. Thus, for a numerical experiment conducted with the same vertical diffusivity and freshwater supply, but with a ten times larger basin area, the turnover time is expected to increase with roughly with a factor of three. Note also that equations (14) and (15) suggest that the pycnocline depth would increase by a factor of three and that the salinity difference would be decreased by a factor of three.

[46] Thus, increasing the basin area by a factor of ten in our numerical experiments, the turnover time is expected to increase roughly by a factor ranging from three to ten, depending on whether the exchange flow is predominantly buoyancy driven or wind driven. Note that since the buoyancy-driven flow increases with basin area, this flow component becomes larger relative to the wind-driven flow component in a larger basin.

[47] As a closing comment, we note that the assumptions on the nature of vertical mixing affect the flow dynamics [Nilsson and Walin, 2001]. In the two-layer model of the paleo Arctic Ocean studied by Jakobsson et al. [2007], the energy supply to the vertical mixing, rather than the vertical diffusivity, was taken to be fixed. This physically based assumption yields the following expression for the upwelling [e.g., Jakobsson et al., 2007]

$$
\psi_{D}=\frac{e A}{g \beta \Delta S H} .
$$

Here, $e$ is the energy supply per unit area to the turbulent vertical mixing. Note that equation (13) still applies since the Rossby radius is independent of the vertical mixing. In this case, equations (9)-(11) and (17) yield after some manipulations the following steady state relations [e.g., Jakobsson et al., 2007; Nilsson and Walin, 2010]

$$
\begin{gathered}
H \propto e A F^{-1}, \\
\Delta \mathrm{S} \propto(\mathrm{e} \mathrm{A})^{-1} \mathrm{~F}^{3 / 2}, \\
\psi \propto e A F^{-1 / 2} .
\end{gathered}
$$

Also in this case, the dependence of the exchange flow on the freshwater supply is weaker than linear. However, the exchange flow now decreases with increasing freshwater supply [Nilsson and Walin, 2010]. Interestingly, equation (20) suggests that the turnover time is independent of the basin area when the energy supply per unit area to the mixing is fixed; the dependence of the pycnocline and the salinity difference on the basin area are also more pronounced in this case. However, for the present numerical experiments that use a typical upper ocean value of the vertical diffusivity [e.g.,
Munk and Wunsch, 1998], equations (14)-(16) are more appropriate for analyzing the influence of the basin area on the flow.

\subsection{Sensitivity of Tracer Age to Horizontal Mixing and Vertical Diffusion}

[48] The model tracer age is sensitive to the horizontal mixing scheme used in the model [England, 1995]. The incorporation of Gent and McWilliams [1990] (GM) parameterization in the model will generate "bolus" velocities, equivalent to layer thickness diffusion appearing as an eddyinduced advection that is added to the mean advective fluxes. Even though the GM scheme can improve the representation of subgrid-scale eddy diffusive processes in coarse resolution models, it may lead to unrealistic strong mixing in eddy-permitting and eddy-resolving models. To estimate the influence of mixing on age tracer simulation, additional model integrations have been done by adding GM parameterization in the experiment Exp1. With the incorporation of this additional mixing, the mean tracer age has decreased by about $15 \%$.

[49] Vertical diffusion could also be important in ventilation studies using passive tracers. Since the age tracer in the model is integrated with the advection-diffusion equations, the interpretation of tracer age can be misleading if the model is too diffusive. In order to examine the role of vertical diffusion in determining the water age, a simple budget analysis of the age tracer has been done based on the model simulation. The details of tracer budget computation are described in Appendix A. The analysis revealed that the contribution of vertical diffusion is generally small relative to the advective process in the age tracer balance.

\section{Discussion}

[50] In the present study, we integrated an ocean model with an age tracer, without the incorporation of any biochemical processes, in order to estimate the oxygenation/ventilation rate in an idealized basin, designed to address questions regarding the early Miocene Arctic Ocean (Figures 1-3). In the model, which has highly simplified basin geometry, the "paleo Arctic Ocean" is a semienclosed basin that communicates through the Fram Strait with the Atlantic Ocean. This configuration is analogous to the early Miocene paleo bathymetric reconstruction compiled by Jakobsson et al. [2007], although prominent bathymetric features such as the Lomonosov Ridge are not represented in our experiments. In the simulations, the ventilation is only achieved by the inflow of young water to the semienclosed Arctic Ocean, since the age tracer is not restored to zero at the surface.

[51] To examine the influence of basin geometry and forcing, sensitivity experiments were performed in which the strait width and the freshwater supply were varied and surface wind stress was introduced. These experiments generally revealed that as the strait width decreases, the tracer age increases. This implies that the tectonic opening of the Fram Strait [Vogt et al., 1979; Engen et al., 2008] is likely to have had a large influence on the Arctic Ocean paleoceanographic evolution as suggested in previous studies [Haley et al., 
2008]. The reduction in the width of the strait by a factor of $\sim 3.5$ leads in the present simulations to an increase of the tracer age by about $15-20 \%$. It should be noted that the strait width started to curtail the exchange flow well before its width became comparable to the internal Rossby Radius (Table 1).

[52] The sill depth is another factor that can influence the exchange flow [Stommel and Farmer, 1953; Walin et al., 2004; Pratt and Spall, 2008; Iovino et al., 2008]. Generally, a shallower sill results in a reduced exchange flow. Dynamically, a sill can decrease the exchange flow by blocking the range of depth contours (more generally geostropic contours) connecting the two basins. Another chocking effect occurs if the upper layer of low-density water is deeper than the sill depth, a situation referred to as an over-mixed flow [Stommel and Farmer, 1953]. To examine the influence of the sill depth on the ventilation process, we carried out an additional experiment with the narrow strait width of $\sim 96 \mathrm{~km}$, where the sill depth was reduced to $250 \mathrm{~m}$ (it was $1000 \mathrm{~m}$ in all other experiments). It showed that the sill depth has an insignificant effect on the tracer distribution in the absence of wind forcing.

[53] Quantitative information about the freshwater input into the Arctic Ocean is not available for the early Miocene. However, given that the global mean surface temperature presumably was rather higher in the early Miocene than today [Zachos et al., 2001], the hydrological cycle should have been relatively stronger [Held and Soden, 2006]. A relatively mild high-latitude climate during the Miocene is also suggested by proxy records of temperate vegetation in the Arctic region [White and Ager, 1994]. Further, severe Arctic continental winter temperatures were restrained by the ice-free Arctic Ocean during early Miocene [McNeil, 1989]. Thus, the higher global surface temperature and the associated strengthening of the hydrological cycle as well as temperate vegetation over the Arctic continental regions suggest that the freshwater input into the early Miocene Arctic Ocean was similar or higher compared to the present day. The simulations revealed that the response in tracer age and transport time scales is marginal when the freshwater flux is increased from 0.16 to $0.2 \mathrm{~Sv}$. To further confirm this, we performed an additional wide-strait experiment without wind forcing, where the freshwater flux was lowered to $0.05 \mathrm{~Sv}$. In this case, the turnover time was increased from 38 to 49 years, roughly consistent with the theoretical relations shown in section 5.4 .

[54] An important outcome of the study is the substantial reduction in the tracer age caused by wind-forced circulation. The decrease in tracer age is significant in the region above the sill depth $(<1000 \mathrm{~m})$. Below the sill depth, the response to the wind forcing is stronger for the maximum tracer age than the mean tracer age. In terms of basin averages, the mean tracer age is decreased by $45-50 \%$ in the wind-forced experiments relative to without wind forcing, whereas the reduction is about $60 \%$ for the maximum tracer age in the basin. Thus, wind driven circulation has wide implication in the studies related to the sedimentation and oxygenation processes in marginal seas and estuaries. The difference in age distribution between the experiments with wide and narrow straits as well as between wind-forced and no-wind experiments are also clearly seen in the frequency distribution of age tracer in the basin $(\chi)$ and the frequency function for the transit time $(\varphi)$. The spectra $\chi$ and $\varphi$ peak at younger age for the wind-forced experiments and the experiments with a wider strait.

[55] The ventilation of the idealized paleo Arctic Ocean basin was examined using simulated age tracer distributions as well as the turnover time. A reasonable agreement was found between the tracer age and turnover time. Generally, the turnover time gives a first hand approximation of the average ventilation time of the basin.

[56] Jakobsson et al. [2007] proposed that the transition of the Arctic Ocean to a fully ventilated oxygenated stage in the early Miocene was caused by the widening and deepening of the Fram Strait. The present simulations of an idealized Arctic Ocean model yield additional information on this paleo oceanographic question. To begin with, there is a transition in the ventilation characteristics at a strait width of above $100 \mathrm{~km}$. For narrower straits, the turnover time based on the net exchange in the strait is longer than the mean (tracer) age of the basin water. For wider straits, on the other hand, the turnover time is shorter than the mean (tracer) age. This result applies both for the experiments with and without wind forcing. Jakobsson et al. [2007] used the turnover time to argue that the Fram Strait must have been about 40 to $50 \mathrm{~km}$ wide before the Arctic Ocean became fully oxygenated. Interestingly, their analysis was based on a strait width that is narrower than $100 \mathrm{~km}$. Accordingly, the present numerical experiments suggest that the turnover time estimate by Jakobsson et al. [2007] should (if their two-layer transport estimate is reasonable) give an upper bound on the mean age of the water in the Arctic Ocean at that stage in the Fram Strait development, since the mean age is smaller than the turnover time for such a narrow strait.

[57] According to paleo bathymetric constructions [Jakobsson et al., 2007], the volume of the early Miocene Arctic Ocean is about 10 times larger than the volume of the northern basin in our model. If we very crudely assume that the turnover time and the mean age scale linearly with the basin volume, then the corresponding time scales for the early Miocene Arctic Ocean would be a factor of 10 larger. For the narrow-strait experiment with wind forcing $(\operatorname{Exp} 3 \mathrm{~W})$, the upscaled turnover time and mean tracer age are about 400 and 300 years, respectively. These time scales are comparable to the turnover time of 250 years that Jakobsson et al. [2007] suggested as the requirement for a fully oxygenated early Miocene Arctic Ocean. Thus, our simulations suggest that early Miocene Arctic Ocean should have been oxygenated when the strait width was on the order of $100 \mathrm{~km}$. Since at least 4-5 grid points across the strait is needed for adequate resolution of the flow, further simulations at higher resolutions will be required to examine strait widths of 40 to $50 \mathrm{~km}$, proposed by Jakobsson et al. [2007] as the threshold width for the onset of oxygenated conditions.

[58] Another interesting issue is the role of directly windforced exchange flow. In the present wind-forced simulations, the inclusion of realistic amplitude of the wind stress 
typically reduces the mean tracer age and the ventilation time by $50 \%$. Thus, although the wind forcing has a significant impact, it does not change the order of magnitude of the mean age in the basin. Furthermore, the wind-driven exchange flow should become weaker in straits narrower than examined in our study. Accordingly, the estimated transition width of 40 to $50 \mathrm{~km}$ of Jakobsson et al. [2007] should be reduced by less than $50 \%$ even when wind-forced circulation is taken into account.

[59] In summary, our study of an idealized Miocene Arctic Ocean reveals that the ventilation time is primarily determined by the wind forcing and the strait width. The sill depth and the freshwater forcing have a relatively weak influence on the turnover time, but can influence the age distribution within the basin. Furthermore, the wind forcing has the strongest impact on the ventilation above the sill depth. Without wind forcing, the well-ventilated layer is only in the halocline, which is shallower than the sill. Another interesting result is that in the experiments without wind forcing, the oldest water in the basin is encountered near the sill level, rather than near the bottom; in the presence of wind forcing the oldest water is encountered below the sill level. Our results suggest that the paleo depth of the ACEX sediment sequence from the Lomonosov Ridge is an important factor to consider when translating local oxygen levels to basin-scale ventilation rates.

[60] In addition to the Fram Strait opening, several other geological events in the world oceans have influenced the geometry of oceanic gateways, with significant consequences for the paleoceanographic evolution. We have previously compared the Arctic Ocean with the Black Sea, where the presently $124 \mathrm{~m}$ deep and $<4 \mathrm{~km}$ wide Bosporus Strait control the water exchange with the Mediterranean Sea.

[61] At the western end of the Mediterranean Sea, the water exchange with the Atlantic through the Gibraltar Strait greatly influences the circulation and stratification in the basin. The narrowest point of the strait is approximately $13 \mathrm{~km}$ wide, and therefore so narrow that the exchange flow is hydraulically controlled, rather than rotationally controlled as in the wider Fram Strait. The depth is constrained by the $284 \mathrm{~m}$ deep Camarinal Sill and the depth at the actual Gibraltar Strait of approximately $900 \mathrm{~m}$.

[62] In the present climate, the strong net evaporation in the Mediterranean Sea results in an antiestuarine circulation, characterized by a surface inflow of Atlantic water. Inside the Mediterranean, the water is enriched in salt, sinks and finally exits at depth through the Gibraltar Strait. Accordingly, the deep water ventilation of the Mediterranean Sea is primarily occurring through convective processes, involving evaporation and cooling. This creates dense waters in the northern basins that sink and transport oxygen to deeper parts [Bethoux et al., 1999]. As a result, the water exchange through the Gibraltar Strait, and hence its physiographic features, should, in contrast to those of the Fram Strait, have a relatively weak influence on the ventilation of the Mediterranean deep water.

[63] Sediment records from the Mediterranean Sea contain recurrent sapropel layers, a feature that is also prominent in the ACEX core and interpreted to document the poorly ventilated estuarine phase of the Arctic Ocean prior to the establishment of a rotationally controlled flow through the Fram Strait [Jakobsson et al., 2007]. The sapropel layers are characterized by a Total Organic Carbon (TOC) content exceeding $2 \%$ in weight and reflect incomplete decomposition under anoxic conditions. In the Mediterranean, the sapropels are thought to have formed during astronomically paced periods of increased freshwater supply and reduced bottom water ventilation [e.g., Rohling et al., 2000]. Possibly, the Mediterranean sapropels reflect the establishment of an estuarine circulation with an outflow of surface water through the Gibraltar Strait [Thunell and Williams, 1989; Rohling et al., 2000].

[64] The estuarine phase of the Arctic Ocean occurred during times when the width of the Fram Strait was narrower than $40-50 \mathrm{~km}$. This physiographic setting is also characterized by sapropel formation, manifested as black layers in the lower part of subunit $1 / 5$ in the ACEX core, with TOC contents between about 5 and $14.5 \%$, intervened by less TOC-rich gray layers [Stein et al., 2006]; see Figure 2. It is thus possible that the circulation and ventilation of the Mediterranean during phases of sapropel formation were qualitatively similar to those of the Arctic Ocean before a vigorous rotationally controlled exchange flow was established in the Fram Strait.

[65] As a closing comment, the idealized nature of the present numerical experiments should be emphasized. Obviously, the results obtained from these simulations fail to describe the full complexity of the ventilation in a semienclosed basin such as the paleo Arctic Ocean. The paleobathymetric reconstruction in Figure 1 reveals complex topographic features such as ridges and abyssal subbasins. The water age in isolated abyssal subbasins presumably can be much greater than the mean age in the present simulations, with a very smooth basin bathymetry. Subsurface ridges stretching across the basin can, on the other hand, give rise to topographically steered currents that stimulates a more efficient mixing in the basin. Accordingly, the effect of more realistic bathymetry on the age of the water in the basin is nontrivial, and will be examined in a future study. Also, the neglect of thermal density differences removes important dynamical processes [e.g., Rudels, 1995; Nilsson and Walin, 2010]. Furthermore, we have only considered the effect of time-independent wind forcing on the ventilation process. In reality, variability due to weather and seasonal changes are of importance for driving the exchange flows. These neglected terms as well as tidal currents act generally to enhance the ventilation and hence to reduce the age of the water in the basin [e.g., Stigebrandt, 1983]. However, to quantify these effects requires additional analysis and numerical simulations beyond the scope of the present study.

\section{Appendix A: Age Tracer Budget}

[66] The age budget analysis is done for water below the sill depth $(1100 \mathrm{~m})$ in the northern basin. The defined volume is closed by lateral and bottom boundaries, and the exchange of water (age) can take place only through the top surface. The age of water inside the volume is affected by the vertical 

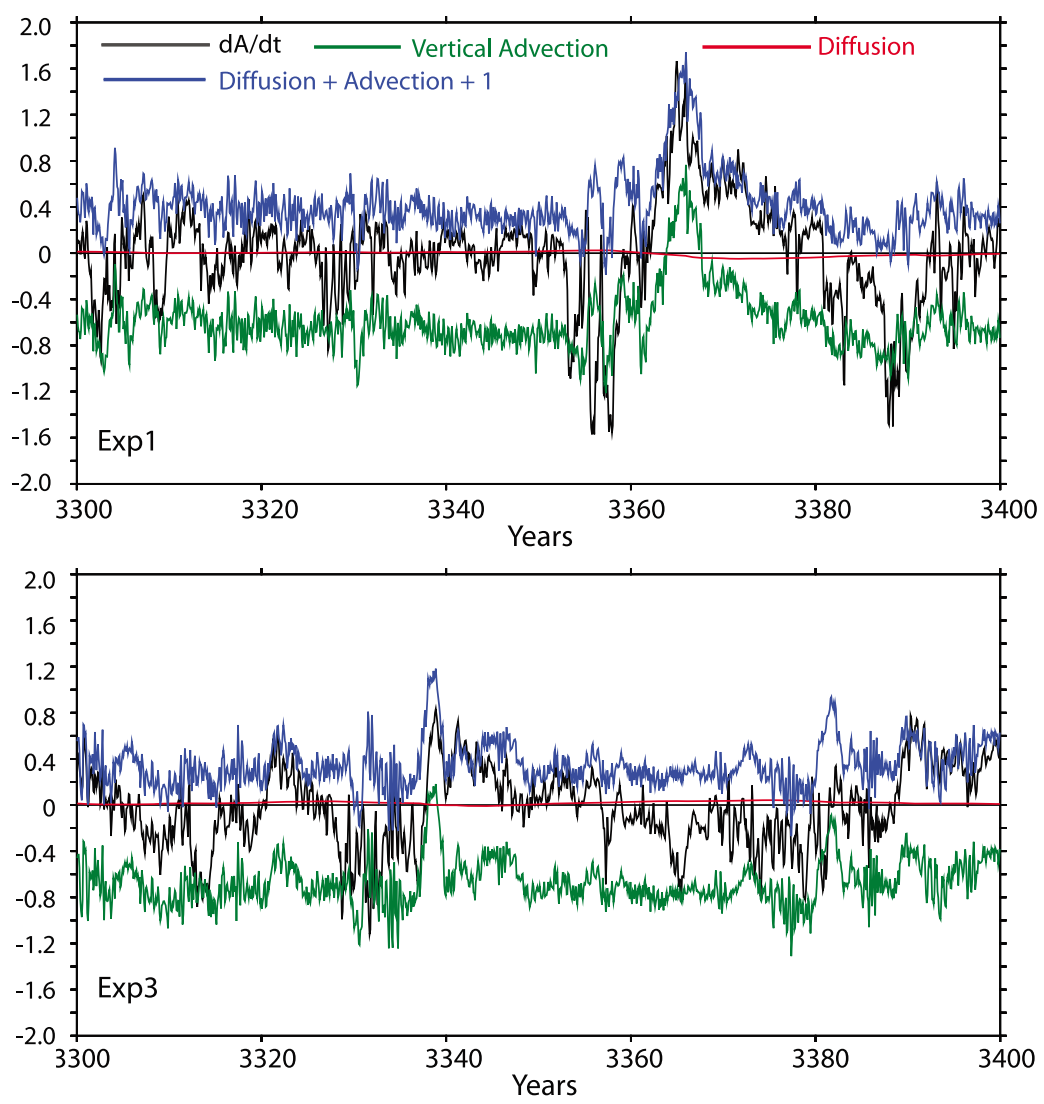

Figure A1. The age tracer budget computed for experiments Exp1 and Exp3 for the last 100 years of model integration. The individual components of the tracer budget are shown. Legends shown in Figure A1 (top) also apply to Figure A1 (bottom). The quantities are dimensionless.

advection and diffusion at the top surface and model aging only. The budget can be written as

$$
\begin{aligned}
\frac{1}{\mathrm{~V}_{1100}} \frac{\mathrm{d}}{\mathrm{dt}} \int_{z=1100}^{z=2000} \iint \tau \mathrm{dxdydz}= & -\frac{1}{\mathrm{~V}_{1100}} \iint\left(\mathrm{W}_{1100 \cdot \tau) \mathrm{dx} \mathrm{dy}}\right. \\
& -\frac{1}{\mathrm{~V}_{1100}} \iint \mathrm{k}\left(\frac{\partial \tau}{\partial \mathrm{z}}\right)_{z=1100} \mathrm{dx} \mathrm{dy}+1 .
\end{aligned}
$$

Here, $\tau$ is the tracer age, $\mathrm{W}_{1100}$ is the vertical velocity at $1100 \mathrm{~m}, \mathrm{k}$ is the vertical diffusivity, which is taken as a constant, and $\mathrm{V}_{1100}$ is the volume of water below the depth $1100 \mathrm{~m}$

[67] The age budgets for the last 100 years of integration for the Exp1 and Exp3 experiments are shown in the Figure A1. The drifts in the age tendency indicate the existence of strong eddy circulations in the model. The encouraging fact is that the drifts are small and change sign. Figure $\mathrm{A} 1$ also shows that the budget is not exactly closed. The important result, however, is that the diffusion is very small compared to other terms in the budget. Thus, the tracer age tendency is mainly determined by the vertical advection of age into the volume.

[68] Acknowledgments. This work was supported by the Bert Bolin Centre for Climate Research, Stockholm University, Sweden. The model integrations were done in the Linux cluster "Tornado" at National Supercomputer Center in Sweden (NSC), and the support from NSC staff is acknowledged. We thank Jan Backman for discussions and comments on the manuscript. We acknowledge the anonymous reviewer and the editor, Christopher Charles, for their invaluable comments, which improved the original manuscript. We also thank Richard D. Slater, Princeton University, for the discussions regarding the implementation of age tracer in the model. Figures were drawn using Ferret and the GIS software GeoMedia Professional.

\section{References}

Andersson, T., and P. Pucar (1995), Estimation of residence time in continuous flow systems with dynamics, J. Process Control, 5, 9-17, doi:10.1016/0959-1524(95)95941-6.

Backman, J., and K. Moran (2008), Introduction to special section on Cenozoic Paleoceanography of the Central Arctic Ocean, Paleoceanography, 23, PA1S01, doi:10.1029/2007PA001516.
Backman, J., and K. Moran (2009), Expanding the Cenozoic paleoceanographic record in the central Arctic Ocean: IODP Expedition 302 synthesis, Cent. Eur. J. Geosci., 1, 157-175, doi:10.2478/v10085-009-0015-6.

Backman, J., et al. (2008), Age model and core-seismic integration for the Cenozoic Arctic Coring Expedition sediments from the Lomonosov Ridge, Paleoceanography, 23, PA1S03, doi:10.1029/2007PA001476. Bethoux, J. P., B. Gentili, P. Morin, E. Nicolas, C. Pierre, and D. Ruiz-Pino (1999), The Mediterranean Sea: A miniature ocean for climatic and environmental studies and a key for the climatic functioning of the North Atlantic, 
Prog. Oceanogr., 44, 131-146, doi:10.1016/ S0079-6611(99)00023-3.

Bolin, B., and H. Rodhe (1973), A note on the concepts of age distribution and residence time in natural reservoirs, Tellus, 25, 58-62, doi:10.1111/j.2153-3490.1973.tb01594.x.

Colella, P., and P. R. Woodward (1984), The piecewise parabolic method (PPM) for gasdynamical simulations, J. Comput. Phys., 54, 174-201, doi:10.1016/0021-9991(84)90143-8.

Cox, M. D. (1989), An idealized model of the world ocean. Part I: The global scale water masses, J. Phys. Oceanogr., 19, 1730-1752, doi:10.1175/1520-0485(1989)019<1730: AIMOTW $>2.0 . \mathrm{CO} ; 2$.

Davies, R., J. Cartwright, J. Pike, and C. Line (2001), Early Oligocene initiation of North Atlantic Deep Water formation, Nature, 410, 917-920, doi:10.1038/35073551.

Deleersnijder, E., J. M. Campin, and E. J. M. Delhez (2001), The concept of age in marine modelling: I. Theory and preliminary model results, J. Mar. Syst., 28, 229-267, doi:10.1016/ S0924-7963(01)00026-4.

Deleersnijder, E., A. Mouchet, E. J. M. Delhez, and J. M. Beckers (2002), Transient behaviour of water ages in the World Ocean, Math. Comput. Modell., 36, 121-127, doi:10.1016/ S0895-7177(02)00108-5.

Delhez, E. J. M., and E. Deleersnijder (2002), The concept of age in marine modelling: II. Concentration distribution function in the English Channel and the North Sea, J. Mar. Syst., 31, 279-297, doi:10.1016/S0924-7963 (01)00066-5

Döös, K., and D. J. Webb (1994), The Deacon Cell and the other meridional cells in the Southern Ocean, J. Phys. Oceanogr., 24, 429-442, doi:10.1175/1520-0485(1994) 024<0429:TDCATO $>2.0$. CO;2

Döös, K., M. Meier, and R. Döscher (2004), The Baltic Haline Conveyor Belt or the overturning circulation and mixing in the Baltic, Ambio, 23, 261-266.

Döös, K., J. Nycander, and A. C. Coward (2008), Lagrangian decomposition of the Deacon Cell, J. Geophys. Res., 113, C07028, doi:10.1029/ 2007JC004351.

Engen, Ø., J. I. Faleide, and T. K. Dyreng (2008), Opening of the Fram Strait gateway: A review of plate tectonic constraints, Tectonophysics, 450, 51-69.

England, M. H. (1995), The age of water and ventilation time-scales in a global ocean model, J. Phys. Oceanogr., 25, 2756-2777, doi: 10.1175/1520-0485(1995)025<2756: TAOWAV $>2.0 . \mathrm{CO} ; 2$.

Garcia-Castellanos, D., F. Estrada, I. JiménezMunt, C. Gorini, M. Fernàndez, J. Vergés, and R. De Vicente (2009), Catastrophic flood of the Mediterranean after the Messinian salinity crisis, Nature, 462, 778-781, doi:10.1038/ nature 08555.

Gent, P. R., and J. C. McWilliams (1990), Isopycnal mixing in ocean circulation models, J. Phys. Oceanogr., 20, 150-155, doi:10.1175/ 1520-0485(1990)020<0150:IMIOCM >2.0. $\mathrm{CO} ; 2$.

Gill, A. E. (1982), Atmosphere-Ocean Dynamics, Int. Geophys. Ser, vol. 30, Academic, London. Govers, R. (2009), Choking the Mediterranean to dehydration: The Messinian salinity crisis, Geology, 37(2), 167-170, doi:10.1130/G25141A.1. Griffies, S. M. (2007), Elements of MOM4p1, GFDL Ocean Group Tech. Rep. 6, Geophys. Fluid Dyn. Lab., NOAA, Princeton, N. J.
Griffies, S. M., and R. W. Hallberg (2000), Biharmonic friction with a Smagorisky viscosity for use in large-scale eddy-permitting ocean models, Mon. Weather Rev., 128, 2935-2946, doi:10.1175/1520-0493(2000) $128<2935$ :BFWASL $>2.0$. CO 2 .

Haine, T. W. N., and J. Marshall (1998), Gravitational, symmetric, and baroclinic instability of the ocean mixed layer, J. Phys. Oceanogr., 28, 634-658, doi:10.1175/1520-0485(1998) $028<0634$ :GSABIO $>2.0 . \mathrm{CO} ; 2$.

Haley, B. A., M. Frank, R. F. Spielhagen, and A. Eisenhauer (2008), Influence of brine formation on Arctic Ocean circulation over the past 15 million years, Nat. Geosci., 1, 68-72, doi:10.1038/ngeo.2007.5.

Held, I. (1999), The macroturbulence of the troposphere, Tellus, Ser. A, 51, 59-70, doi:10.1034/ j.1600-0870.1999.t01-1-00006.x.

Held, I. M., and B. J. Soden (2006), Robust response of the hydrological cycle to global warming, J. Clim., 19, 5686-5699, doi:10.1175/JCLI3990.1

Hirst, A. C. (1999), Determination of water component age in ocean models: Application to the fate of North Atlantic Deep Water, Ocean Modell., 1, 81-94, doi:10.1016/S1463-5003 (99)00010-4.

Hsü, K. J., W. B. F. Ryan, and M. B. Cita (1973), Late Miocene desiccation of the Mediterranean, Nature, 242, 240-244, doi:10.1038/ $242240 \mathrm{a} 0$.

Iovino, D., F. Straneo, and M. A. Spall (2008), On the effect of a sill on dense water formation in a marginal sea, J. Mar. Res., 66(3), 325-345, doi:10.1357/002224008786176016.

Jakobsson, M., et al. (2007), The early Miocene onset of a ventilated circulation regime in the Arctic Ocean, Nature, 447, 986-990, doi:10.1038/nature05924.

Jakobsson, M., R. Macnab, L. Mayer, R. Anderson, M. Edwards, J. Hatzky, H. W. Schenke, and P. Johnson (2008), An improved bathymetric portrayal of the Arctic Ocean: Implications for ocean modeling and geological, geophysical and oceanographic analyses, Geophys. Res. Lett., 35, L07602, doi:10.1029/2008GL033520.

Jönsson, B., P. Lundberg, and K. Döös (2004), Baltic sub-basin turnover times examined using the Rossby Centre Ocean Model, Ambio, 33, 257-260.

Kaminski, M. A., L. Silye, and S. Kender (2009), Miocene deep-water agglutinated foraminifera from the Lomonosov Ridge and the opening of the Fram Strait, Micropaleontology, 55, 117-135.

Karlson, K., R. Rosenberg, and E. Bonsdorff (2002), Temporal and spatial large-scale effects of eutrophication and oxygen deficiency on benthic fauna in Scandinavian and Baltic waters: A review, Oceanogr. Mar. Biol., 40, 427-489.

Karsten, R., H. Jones, and J. Marshall (2002), The role of eddy transfer in setting the stratification and transport of a circumpolar current, J. Phys. Oceanogr., 32, 39-54, doi:10.1175/ 1520-0485(2002)032<0039:TROETI $>2.0$. $\mathrm{CO} ; 2$.

Khatiwala, S., M. Visbeck, and P. Schlosser (2001), Age tracers in an ocean GCM, Deep Sea Res., Part I, 48, 1423-1441, doi:10.1016/ S0967-0637(00)00094-7.

Khatiwala, S., M. Visbeck, and M. Cane (2005), Accelerated simulation of passive tracers in ocean circulation models, Ocean Modell., 9, 51-69.
Klenke, M., and H. W. Schenke (2002), A new bathymetric model for the central Fram Strait, Mar. Geophys. Res., 23, 367-378, doi:10.1023/ A:1025764206736.

Krijgsman, W., F. J. Hilgen, I. Raffi, F. J. Sierro, and D. S. Wilson (1999), Chronology, causes and progression of the Messinian salinity crisis, Nature, 400, 652-655, doi:10.1038/23231.

Large, W. G., J. C. McWilliams, and S. C. Doney (1994), Oceanic vertical mixing: A review and a model with a nonlocal boundary layer parameterization, Rev. Geophys., 32, 363-403, doi:10.1029/94RG01872.

McNeil, D. H. (1989), Foraminiferal zonation and biofacies analysis of Cenozoic strata in the Beaufort-Mackenzie Basin of Arctic Canada, in Current Research, Part G, Pap. Geol. Surv. Can., 89-1G, 203-223.

Merryfield, W. J., and G. Holloway (2003), Application of an accurate advection algorithm to sea-ice modelling, Ocean Modell., 5, 1-15, doi:10.1016/S1463-5003(02)00011-2.

Monsen, N. E., J. E. Cloern, L. V. Lucas, and S. G. Monismith (2002), A comment on the use of flushing time, residence time and age as transport time scales, Limnol. Oceanogr., 47(5), 1545-1553, doi:10.4319/1o.2002.47.5.1545.

Munk, W. H., and C. Wunsch (1998), Abyssal recipes II: Energetics of tidal and wind mixing, Deep Sea Res., Part I, 45, 1977-2010, doi:10.1016/S0967-0637(98)00070-3.

Nilsson, J., and G. Walin (2001), Freshwater forcing as booster of thermohaline circulation, Tellus, Ser. A, 53, 629-641.

Nilsson, J., and G. Walin (2010), Salinitydominated thermohaline circulation in sill basins: Can two stable equilibria exist?, Tellus Ser. A, 62, 123-133, doi:10.1111/j.1600-0870. 2009.00428.x.

Nilsson, J., G. Walin, and G. Broström (2005), Thermohaline circulation induced by bottom friction in sloping-boundary basins, $J$. Mar. Res., 63, 705-728, doi:10.1357/ 0022240054663222

Nilsson, J., G. Björk, B. Rudels, P. Winsor, and D. Torres (2008), Late-winter conditions and Liquid freshwater transport and Polar Surface Water characteristics in the East Greenland Current during the AO-02 Oden expedition, Prog. Oceanogr., 78(1), 45-57, doi:10.1016 j.pocean.2007.06.002.

Nøst, O. A., and P. E. Isachsen (2003), The large-scale time-mean ocean circulation in the Nordic Seas and Arctic Ocean estimated from simplified dynamics, J. Mar. Res., 61, 175-210, doi:10.1357/002224003322005069.

Nøst, O. A., J. Nilsson, and J. Nycander (2008), On the asymmetry between cyclonic and anticyclonic flow in basins with sloping boundaries, J. Phys. Oceanogr., 38, 771-787, doi:10.1175/ 2007JPO3714.1.

Prather, M. (1986), Numerical advection by conservation of second-order moments, J. Geophys. Res., 91, 6671-6681, doi:10.1029/ JD091iD06p06671

Pratt, L. J., and M. A. Spall (2008), Circulation and exchange in choked marginal seas, J. Phys Oceanogr., 38, 2639-2661, doi:10.1175/ 2008JPO3946.1.

Risien, C. M., and D. B. Chelton (2006), A satellite derived climatology of global ocean winds, Remote Sens. Environ., 105, 221-236, doi:10.1016/j.rse.2006.06.017.

Rohling, E. J., S. De Rijik, P. G. Myers, and K. Haines (2000), Palaeoceanography and numerical modelling: The Mediterranean 
Sea at times of sapropel formation, Geol. Soc. Spec. Publ., 181, 135-149.

Rudels, B. (1995), The thermohaline circulation of the Arctic Ocean and the Greenland Sea, Philos. Trans. Phys. Sci. Eng., 352, 287-299, doi:10.1098/rsta.1995.0071.

Rudels, B., L. Anderson, P. Eriksson, E. Fahrbach, M. Jakobsson, P. Jones, H. Melling, S. Prinsenberg, U. Schauer, and T. Yao (2010), Observations in the ocean, in Arctic Climate System Study (ACSYS), edited by P. Lemke, in press.

Sangiorgi, F., H.-J. Brumsack, D. A. Willard, S. Schouten, C. E. Stickley, M. O'Regan, G.-J. Reichart, J. S. Sinninghe Damsté, and H. Brinkhuis (2008), A 26 million year gap in the central Arctic record at the greenhouseicehouse transition: Looking for clues, Paleoceanography, 23, PA1S04, doi:10.1029/ 2007PA001477.

Spall, M. A. (2004), Boundary currents and water mass transformation in marginal seas, J. Phys. Oceanogr., 34, 1197-1213, doi:10.1175/ 1520-0485(2004)034<1197:BCAWTI >2.0. $\mathrm{CO} ; 2$.

Stanev, E. V. (2005), Understanding Black Sea dynamics: Overview of recent numerical modelling, Oceanography, 18(2), 52-71.

Stein, R., B. Boucsein, and H. Meyer (2006), Anoxia and high primary production in the Paleogene central Arctic Ocean: First detailed records from Lomonosov Ridge, Geophys. Res. Lett., 33, L18606, doi:10.1029/ 2006 GL026776.

Stigebrandt, A. (1981), A mechanism governing the estuarine circulation in deep, strongly stratified fjords, Estuarine Coastal Shelf. Sci., 13, 197-211, doi:10.1016/S0302-3524(81)80076-X.
Stigebrandt, A. (1983), A model for the exchange of water and salt between the Baltic and the Skagerrak, J. Phys. Oceanogr., 13, 411-427, doi:10.1175/1520-0485(1983) 013<0411:AMFTEO > 2.0.CO;2.

Stocker, T. F., D. G. Wright, and W. S. Broecker (1992), The influence of high-latitude surface forcing on the global thermohaline circulation, Paleoceanography, 7(5), 529-541, doi:10.1029/92PA01695.

Stommel, H., and H. G. Farmer (1953), Control of salinity in an estuary by a transition, J. Mar Res., 12, 13-20.

Tanhua, T., E. P. Jones, E. Jeansson, S. Jutterström W. M. Smethie Jr., D. W. R. Wallace, and L. G. Anderson (2009), Ventilation of the Arctic Ocean: Mean ages and inventories of anthropogenic $\mathrm{CO}_{2}$ and CFC-11, J. Geophys Res., 114, C01002, doi:10.1029/2008JC004868.

Thunell, R. C., and D. F. Williams (1989), Glacial-Holocene salinity changes in the Mediterranean Sea: Hydrographic and depositional effects, Nature, 338, 493-496, doi:10.1038/338493a0.

Torsvik, T. H., D. Carlos, J. Mosar, L. R. M Cocks, and T. Malme (2002), Global reconstructions and North Atlantic palaeogeography 400 Ma to Recent, in BATLAS-Mid Norway Plate Reconstructions Atlas With Global and Atlantic Perspectives, coordinated by E. A. Eide, pp. 18-39, Geol. Sur. of Norway, Trondheim, Norway.

Via, R. K., and D. J. Thomas (2006), Evolution of Atlantic thermohaline circulation: Early Oligocene onset of deep-water production in the North Atlantic, Geology, 34, 441-444, doi:10.1130/G22545.1.

Vogt, P. R., P. T. Taylor, L. C. Kovacs, and G. L. Johnson (1979), Detailed aeromagnetic investigation of the Arctic Basin, J. Geophys. Res., 84, 1071-1089, doi:10.1029/ JB084iB03p01071

Waddell, L. M., and T. C. Moore (2008), Salinity of the Eocene Arctic Ocean from oxygen isotope analysis of fish bone carbonate, Paleoceanogra phy, 23, PA1S12, doi:10.1029/2007PA001451.

Walin, G., G. Broström, J. Nilsson, and O. Dahl (2004), Baroclinic boundary currents with downstream decreasing buoyancy; a study of an idealized Nordic Sea system, J. Mar. Res. 62, 517-543, doi:10.1357/0022240041850048.

Welander, P. (1971), The thermocline problem, Philos. Trans. R. Soc. London, Ser. A, 270, 415-421, doi:10.1098/rsta.1971.0081.

White, J. M., and T. A. Ager (1994), Palynology, paleoclimatology and correlation of middle Miocene beds from Porcupine River (Locality 90-1) Alaska, Quat. Int., 22-23, 43-77, doi:10.1016/1040-6182(94)90006-X

Zachos, J., M. Pagani, L. Sloan, E. Thomas, and K. Billups (2001), Trends, rhythms and aberrations in global climate $65 \mathrm{Ma}$ to present, Science 292, 686-693, doi:10.1126/science.1059412.

Zimmerman, J. T. F. (1988), Estuarine residence times, in Hydrodynamics of Estuaries, edited by B. Kjerfve, pp. 75-84, CRC Press, Boca Raton, Fla.

M. Jakobsson and B. Thompson, Department of Geological Sciences, Stockholm University, SE-Stockholm 10691, Sweden. (bijoymet@ gmail.com)

K. Döös, J. Nilsson, and J. Nycander Department of Meteorology, Stockholm University, SE-10691 Stockholm, Sweden. 